\title{
METÁFORA Y GÉNERO: ESTUDIO PROTOTÍPICO DE LAS METÁFORAS DE GÉNERO EN LA PUBLICIDAD DE LA REVISTA BRITISH COSMOPOLITAN ${ }^{1}$
}

\author{
MARISOL VELASCO SACRISTÁN \\ Universidad de Valladolid
}

\begin{abstract}
This research introduces the issue of advertising gender metaphors and their presence in the advertising of British Cosmopolitan, a women's magazine. After providing a theoretical background that interrelates advertising, gender and metaphor, we have focused firstly on advertising metaphors and secondly on gender advertising metaphors, illustrating their presence in the magazine under study. In this paper we have used a sample of 1142 print ads published in 12 issues of British Cosmopolitan in 1999 and 2000².
\end{abstract}

\section{RESUMEN}

Este artículo introduce el tema de las metáforas publicitarias de género y su presencia en la publicidad de una revista femenina concreta, British Cosmopolitan. Tras presentar un marco teórico introductorio sobre la relación entre la publicidad, el género y las metáforas, nos hemos centrado en primer lugar en las metáforas publicitarias y en segundo lugar en las metáforas publicitarias de género, ilustrando su presencia en la revista estudiada. Hemos empleado aquí una muestra de 1142 anuncios publicados en 12 ejemplares de la revista British Cosmopolitan de 1999 y 2000.

\section{INTRODUCCIÓN}

El término "metáfora de género" es una acuñación de Fuertes Olivera (1999) que designa a aquella metáfora cuya proyección conceptual (mapping) pone de relieve una relación de discriminación (en sus múltiples manifestaciones: desigualdad, subordinación, dependencia, etc.) motivada por razón de sexo y dirigida mayoritariamente hacia el

\footnotetext{
${ }^{1}$ Trabajo elaborado dentro del marco del proyecto "INFOGÉNERO: Sistema bilingüe inglés-español de información y gestión del conocimiento en el campo de los estereotipos de género", financiado por el Ministerio de Trabajo y Asuntos Sociales, (I+D+I 27/01).
} 
sexo femenino. Esta discriminación, pese a aparecer motivada por el dimorfismo biológico entre hombres y mujeres (sexo), adquiere carta de naturaleza gracias a la percepción social del mismo (género). Ello justifica que se las denomine "de género" y no "sexuales" (Mey, 1984: 278) o "sexistas". El llamar, por otro lado, "sexistas" a estas metáforas podría implicar que las metáforas tienen capacidad, por sí mismas, de ser discriminatorias, lo que no es cierto. De este modo, podemos decir que las metáforas de género devienen en recursos sexistas cuando se interpretan como mecanismos que discriminan a uno de los dos sexos $^{3}$. No debemos olvidar que el sexismo es de origen pragmático, por lo que no se ha de culpar a la lengua como sistema de desencadenar esta situación, sino al uso que se hace de ella (García Meseguer, 1994; Ross, 1996/1998/1999; Doyle, 1998; Velasco Sacristán, 2002).

En línea con este planteamiento ilustraremos aquí la presencia de las metáforas publicitarias de género en la publicidad de la revista femenina British Cosmopolitan ${ }^{4}$.

Tres componentes teóricos, procedentes de diferentes áreas de investigación, aparecen claramente interrelacionados con el tema de estudio que nos ocupa: la publicidad como vehículo de transmisión y mantenimiento de una asimetría social injusta; el género, y su presencia en el sexismo peculiar del discurso publicitario, de índole semiótica; y la metáfora que, como fenómeno heurístico-axiológico, imprime una ideología que justifica a veces una discriminación por razón de sexo.

\section{a. La publicidad}

La publicidad, como fenómeno interdisciplinar y transdisciplinar, suscita el interés de estudios de muy diversa envergadura (económicos, sociológicos, psicológicos, antropológicos, lingüísticos y semióticos) (Velasco Sacristán, 2002).

En el ámbito lingüístico, tras unas décadas de aparente desinterés por el estudio del lenguaje publicitario, se produjo hacia finales de los años 60 y principios de la década de los 70 una proliferación de estudios descriptivos del lenguaje publicitario (Huertas, 1967; Hernando, 1970; Cardona y Berasarte, 1972; Barros García, 1977, 1978; Ferraz Martínez, 1993; Ferrer Rodríguez, 1994; Mourelle de Lema, 1994). A estos estudios se sumaron

\footnotetext{
${ }^{2}$ Esta muestra fue empleada en el estudio empírico de mi tesis doctoral: "Publicidad y Género: Propuesta, diseño y aplicación de un modelo de análisis de las metáforas de género en la publicidad impresa en lengua inglesa", defendida en noviembre de 2002.

${ }^{3}$ Es importante someter la interpretación de las metáforas publicitarias de género a la consideración de informantes para llegar a un consenso sobre aquellas metáforas que efectivamente se interpretan mayoritariamente como "sexistas" en un contexto socio-cultural concreto (i.e. lectores de una revista femenina específica). Por ello, mantenemos aquí el carácter de "probabilidad” de la interpretación sexista de este tipo de metáforas, que habrá de ponerse a prueba con un grupo de informantes. Esta comprobación empírica de la muestra textual manejada pretende realizarse en el marco del proyecto "INFOGÉNERO" a lo largo de los años 2003 y 2004).

${ }^{4}$ Revista legendaria publicada por primera vez hace treinta años, que se edita en aproximadamente 50 países y que es leída por más de veinte millones de lectores. Destaca por su contenido sobre la pareja, el trabajo, moda, belleza, personajes, tiempo libre, etc. El lenguaje del que se sirve es accesible y cuidado, $\mathrm{y}$ ofrece una imagen vanguardista, un diseño funcional y una publicidad de impacto. Se caracteriza asimismo por una marcada ideología de liberación sexual y laboral [Winship, 1987; folleto publicitario de ESS Subscription Service; British Cosmopolitan (noviembre de 2002)].
}

Odisea, $n^{\circ} \quad 4,2003$ 
también los realizados desde los tres paradigmas lingüísticos. De estos el que más análisis ha generado ha sido el funcionalismo (García Berrio, 1979; Dyer, 1982; Pateman, 1983; Cook, 1992; Campos Pardillos, 1994; Tanaka, 1994; Goddard, 1998; Díaz Pérez, 2000; Fuertes Olivera et al., 2001), seguido del paradigma del estructuralismo (Leech, 1966; Leymore, 1975; Brown, 1997). En tercer lugar, apenas si hay contribuciones generativistas al estudio del lenguaje publicitario (Bruthiaux, 1996; González Martín, 1996).

Las características del lenguaje publicitario (multiplicidad de signos, códigos, textos y contextos) dan cuenta de la dimensión sincrética (y, por tanto, supralingüística) en que se sitúa la comunicación publicitaria, lo que supone un objeto de difícil estudio para la lingüística. Por este motivo, la semiótica publicitaria se perfila en las últimas décadas como una aproximación alternativa y superadora de la investigación lingüística sobre la publicidad. Los estudios sobre la semiótica publicitaria se han llevado a cabo desde corrientes teóricas como la retórica (Barthes, 1957/1980; 1964, 1967; Bonsiepe, 1969; Durand, 1970; Eco, 1976, 1978; Peninou, 1976), la teoría de la información (Chébat y Henault, 1974), la semántica (Castagnotto, 1970; Di Sparti, 1975; Moragas, 1980) o el análisis del discurso (Feliu, 1984; Moriyón Mójica, 1994). Es precisamente desde esta última aproximación teórica desde donde se va consiguiendo paulatinamente una cierta sistematización en los enfoques, perspectivas y metodología. En este modelo se observa una preferencia generalizada por la consideración de la publicidad como práctica discursiva. Es en la actualidad esta corriente, aunque planteada desde el marco teórico del "análisis crítico del discurso", la que cuenta con un mayor número de estudios (Fowler et al., 1978; Kress y Hodge, 1979; Pêcheux, 1982; Mey, 1985; Fairclough, 1989, 1992; Kress, 1989; Hodge y Kress, 1993).

El análisis crítico del discurso intenta contribuir a elevar el estado de conciencia crítica sobre el poder del lenguaje en la sociedad, sentando así las bases de una posible emancipación social (Fairclough, 1989: ix-x). En este modelo teórico se integra el análisis textual, los procesos socio-cognitivos que implica el texto y el contexto socio-cultural en que reside éste (Fairclough, 1989: ix-x). Se inicia, de este modo, un enfoque hermenéuticointerpretativo que pretende, no ya decodificar simplemente el discurso, sino interpretarlo mediante el análisis del discurso en su adecuación a las representaciones cognitivas que los seres humanos tienen almacenados en la memoria a corto plazo (Fairclough, 1989: 11). La utilidad teórica y viabilidad empírica de esta nueva aproximación del análisis crítico del discurso justifica, en definitiva, la multitud de estudios que sobre el lenguaje y el género se han hecho desde el mismo; en primer lugar, el papel de la ideología en el lenguaje (Mey, 1985; Fairclough, 1989, 1992; Gal, 1989; Kress, 1989; Fairclough y Wodak, 1997); y en segundo lugar, la construcción del género en discursos generales y específicos (Stubbs, 1992, 1996; Talbot, 1992, 1995; Mewe Fernández, 1996; Johnson y Meinhoff, 1997).

Cabe, en suma, atribuirle al análisis crítico del discurso el mérito indiscutible de deconstruir la solidez de lo obvio en discursos en los que, como la publicidad, se encarnan ciertas ideologías que legitiman, directa o indirectamente, relaciones sociales asimétricas. Todo ello nos lleva a la propuesta de este enfoque como el marco teórico idóneo para el estudio de las metáforas de género, entendidas como manifestaciones asimétricas del dis- 
curso publicitario. Nos adentramos ahora, por tanto, en el estudio de la construcción asimétrica del género en el discurso publicitario.

\section{b. El género}

En la investigación sobre el género en los medios de comunicación predominan dos aspectos: la influencia de estos medios en la identidad de los individuos y la construcción ideológica del género en los medios de comunicación. El primer aspecto es abordado principalmente desde las nuevas teorías feministas y posfeministas, en las que predominan tres tipos de análisis: (1) estudios feministas sobre la cultura (Schwichtenberg, 1993; Hermes, 1995; Edwards, 1997; Mc An Ghail, 1996; Nixon, 1996; Harding, 1998; Jackson et al., 2001); (2) estudios sobre la nueva investigación de la "teoría homosexual" (queer theory) (Foucault, 1984; Butler, 1990; Merquior, 1991; Bristow, 1997; Whatling, 1997; Kendall y Wickham, 1999); y (3) estudios colaterales procedentes de una investigación más general desde la teoría cultural y crítica (Strinati, 1995; Stuart, 1998; Brooker, 1999; Billingham, 2001). Por otro lado, se aborda el estudio de la construcción ideológica del género en los medios de comunicación desde el "análisis crítico del discurso" (Talbot, 1992, 1995; Mewe Fernández, 1996; Heywood, 1997; Johnson y Finlay, 1997; Neff Van Aertselaer, 1997).

La bibliografía sobre el género en la publicidad comprende estudios de muy diversa índole (social, antropológica, social, etc.) destacando tres tipos de análisis: análisis de contenido (Courtney y Lockeretz, 1971; Belkaoui y Belkaoui, 1976; Goffman, 1976; Pingree et al., 1979; Umiker-Sebeok, 1979/1981/1985; Craig, 1992; Brown, 1997); análisis pragmáticos (Stuteville, 1971; Wilson y Moore, 1979; Levere, 1974; Leff, 1980; Killbourne, 1990; Duffy, 1994; Hubbard, 1994); y análisis críticos (Friedan, 1963; Berger, 1972; Dyer, 1982; Manca y Manca, 1994; Taflinger, 1996; Pérez Chico, 2001; García Nieto, 2001).

En cuanto a los medios de comunicación y el sexismo, hay que señalar que estos son muy proclives a la proliferación del sexismo siendo especialmente pernicioso e insidioso el empleo de la estereotipización de sexos (Fasold et al., 1990; Talbot, 1995). Los intentos por llevar a cabo una reforma lingüística en los mismos han sido múltiples y los frutos que han deparado parecen constatar cambios sustanciales en relación a la representación de los sexos en los medios impresos, sobre todo en lo referente a la terminología profesional neutra y el uso de genéricos no sexistas (i.e. "businessperson") (Cooper, 1984; Meyerhoff, 1984).

Por lo que se refiere a la construcción asimétrica del género en la publicidad, es necesario señalar aquí que los mensajes publicitarios presentan un tipo peculiar de sexismo que, en línea con el tipo de lenguaje propio de la publicidad (sincrético), trasciende el límite de los verbal. Parece adecuado, por ello, referirnos a este tipo de sexismo como "semiótico". Este término, sexismo semiótico, permite clasificar formas asimétricas no exclusivamente verbales que tienen lugar en códigos de naturaleza verbal, sensorial o híbrida, como los que se inscriben en el lenguaje publicitario. El sexismo semiótico es un tipo peculiar de sexismo social, que se manifiesta normalmente a nivel implícito en el 
lenguaje publicitario y que puede adoptar formas no exclusivamente verbales (Velasco Sacristán, 2002: 407). Una de estas formas es, como vamos a ver, la metáfora publicitaria de género.

\section{c. La metáfora}

La metáfora constituye un importante recurso ideológico que permite inculcar ideología de forma soterrada en discursos persuasivos como el político o el publicitario (Fairclough, 1989: 119-120 y Thomas y Wareing, 1999: 43). A menudo coinciden la intención y el ambiente cognitivo del emisor y el del receptor, especialmente cuando se emplean para abordar problemas sociales (i.e. enfermedades) intentando con ello aminorar los efectos que tendría un lenguaje denotativo (Fairclough, 1989: 120). No sucede, sin embargo, lo mismo cuando se emplean para inculcar modelos discriminatorios impulsados por grupos hegemónicos, como ocurre con el capitalismo o el androcentrismo.

El potencial ideológico de la metáfora proviene, en realidad, de su valor cognitivo, que la convierte en un recurso útil para presentar un tipo de experiencia mediante otra, creando así una ideología específica.

La concepción cognitiva de la metáfora comenzó a germinar a mediados de los años 70 , dando al traste con los estudios literalistas anteriores sobre la figura que consideraban que la metáfora era un fenómeno retórico, léxico, de carácter semántico, artificial, periférico y anómalo (Russell, 1976, 1992; Ricoeur, 1978; Aarts y Calbert, 1979; Ortony, 1979; Sacks, 1979; Searle, 1979; Weiner, 1984; MacCormac, 1985; Gentner et al., 1989; Wilks et al., 1991). Se plantea, por primera vez, en especial con los estudios de Lakoff y Johnson (1980) y Lakoff y Turner (1989) que la metáfora es un elemento cognitivo que se refleja en el lenguaje y que constituye un fenómeno heurístico, de naturaleza cognitiva, central, sistemática y necesaria (Lakoff y Johnson, 1980; Harnard, 1982; Lakoff y Turner, 1989; Sweetser, 1990/1993; Indurkhya, 1992; Steen, 1994; Boers, 1996; McGlone, 1996; Turner y Fauconnier, 1998, 2000).

Creemos, en definitiva, que la metáfora publicitaria debe analizarse en el marco de la lingüística cognitiva que entiende ésta como un mecanismo heurístico que crea o refleja valores sociales que el receptor (normalmente el consumidor) interpreta en un contexto sociocultural concreto. Veamos, a continuación, el papel que juega la metáfora en el discurso publicitario.

\section{LA METÁFORA PUBLICITARIA}

Aunque las metáforas publicitarias son muy abundantes en el discurso publicitario, se puede hablar, por un lado, de una escasez de estudios al respecto (McQuarrie y Mick, 1996) y, por otro lado, de una excesiva consideración de la misma como mero recurso estilístico, comparándola en muchos ocasiones con la metáfora literaria (Leech, 1966; Bousoño, 1970; Cohen, 1970; Spang, 1979; Gómez Moreno, 1993).

Sin embargo, la metáfora publicitaria no es sólo, como venimos afirmando, un ornamento estético sino un recurso conceptual con valor heurístico, que permite concebir un 
concepto en términos de otro (Velasco Sacristán, 2002: 505). Su empleo en la publicidad se reviste de las siguientes características específicas (Velasco Sacristán, 1999; Velasco Sacristán y Fuertes Olivera, 2001; Velasco Sacristán, 2002):

1. Se emplea para caracterizar principalmente el producto o servicio anunciado que es, por lo general, el primer término (literal) de la metáfora (Forceville, 1996: 115, 121) con una serie de rasgos relacionados con el mismo, como por ejemplo, el receptor o usuario (hombre o mujer), su precio, origen o naturaleza, tamaño, forma, color, utilidad o efecto que se producen (Barros García, 1977; Cook, 1992; Chandler, 1994; Velasco Sacristán, 2002), que constituyen el segundo elemento (figurado) de la metáfora.

\section{EJEMPLOS:}

\section{[1] EL PERFUME ES UNA MUJER:}

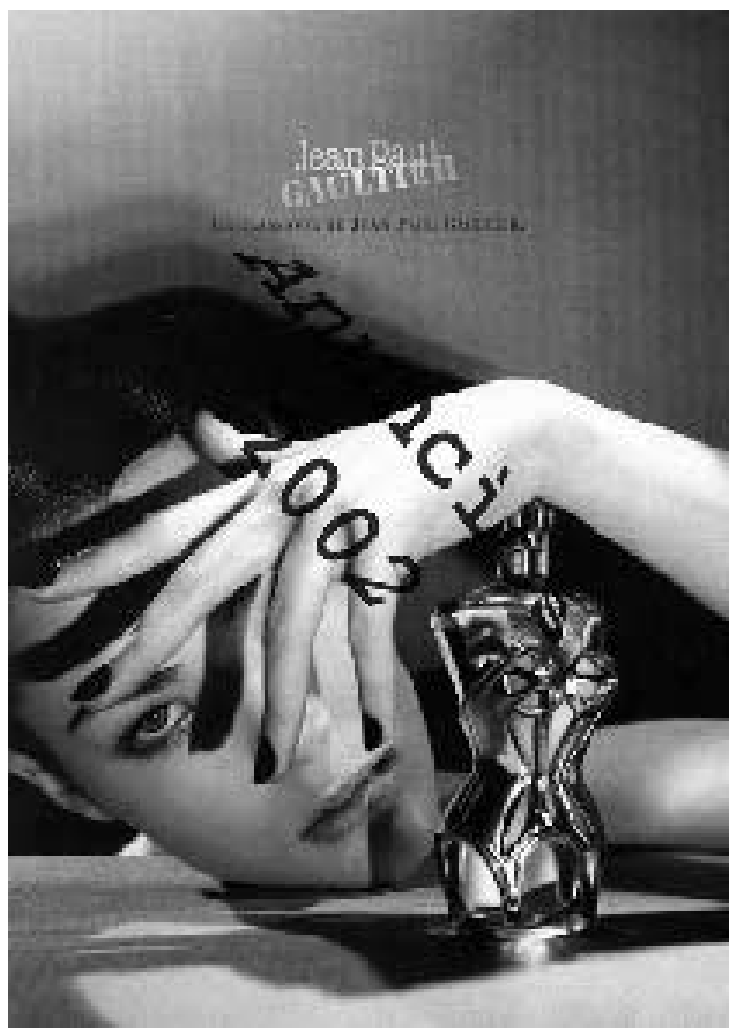

- primer elemento: el perfume femenino "Jean Paul Gautier"

- segundo elemento: una mujer (usuaria del producto).

\footnotetext{
${ }^{5}$ Los ejemplos muestran la imagen escaneada de los anuncios en que se encuentran las metáforas. Cada uno de estos anuncios lleva una marca de agua con el nombre de la base de datos, Anuncios 2002, en la que se almacenan para su empleo en mi tesis doctoral.
}

Odisea, $n^{\circ} 4,2003$ 


\section{[2] EL COCHE ES UNA BAÑERA EN LA QUE CABE UNA BALLENA:}

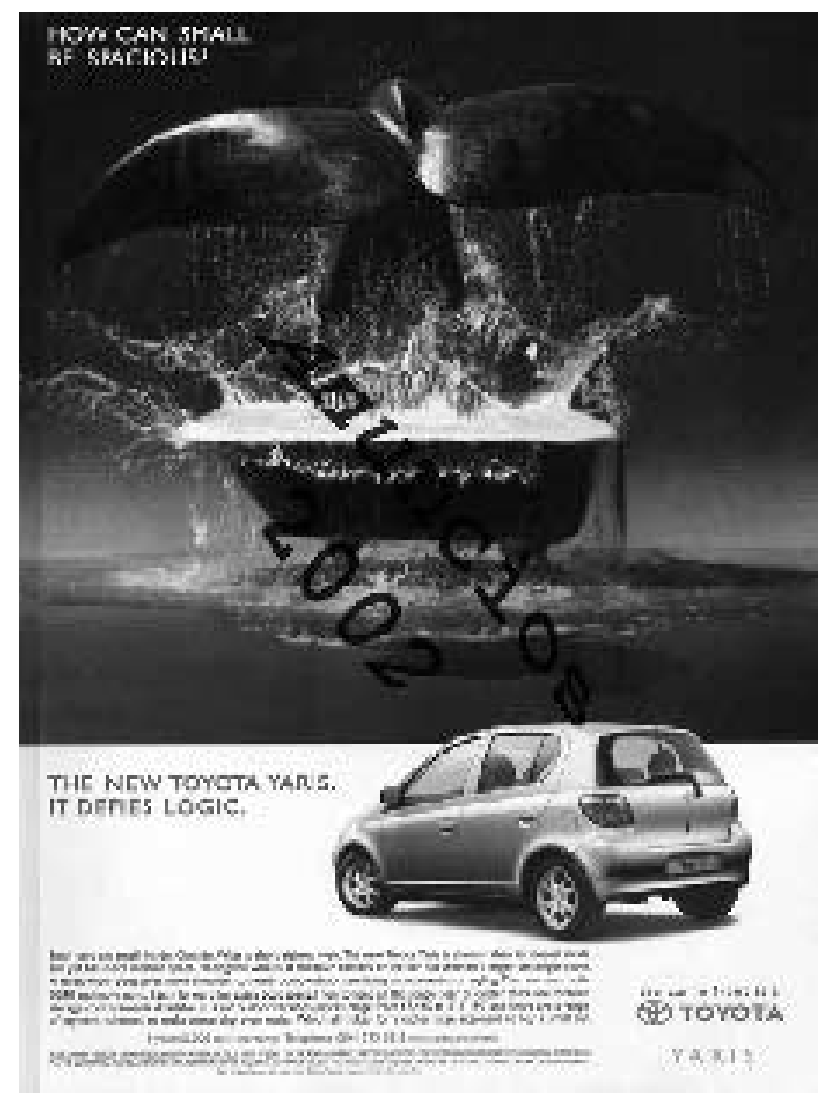

- primer elemento: el automóvil "Toyota Yaris"

- segundo elemento: una bañera en la que cabe una ballena (capacidad: utilidad del producto). 
[3] EL LAVAVAJILLAS ES UN PERFUME:

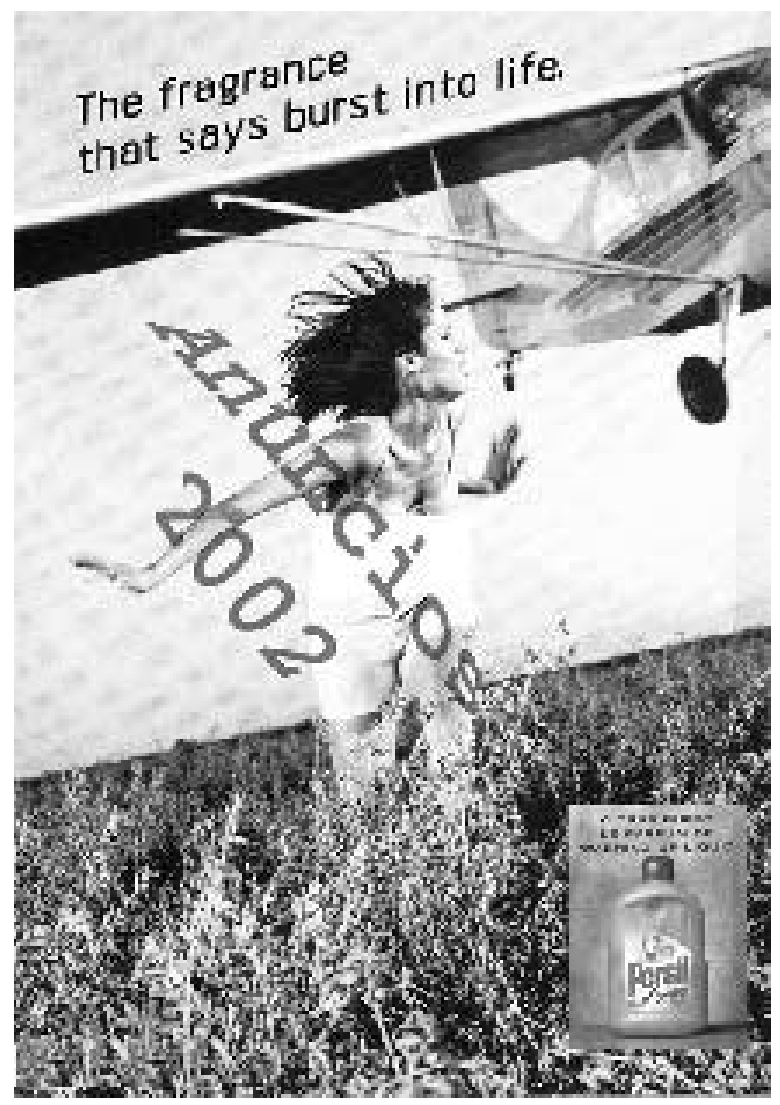

- primer elemento: lavavajillas "Persil Citrus"

- segundo elemento: un perfume (efecto que causa el producto).

2. Existen tres tipos de metáforas conceptuales publicitarias, que coinciden con los tres tipos de metáforas conceptuales que propone Indurkhya, (1992: 1): (a) metáforas convencionales (conventional metaphors), que son aquellas que han perdido por completo su carácter metafórico; (b) metáforas basadas en una similitud (similarity-based metaphors) ya existente entre el primer y el segundo elemento; y (c) metáforas creadoras de similitud (similarity-creating metaphors), en las que no existe similitud entre el campo origen y el meta, puesto que ésta surge una vez que se ha producido la metáfora. 


\section{EJEMPLOS:}

[4] EL PERFUME ES AGUA:

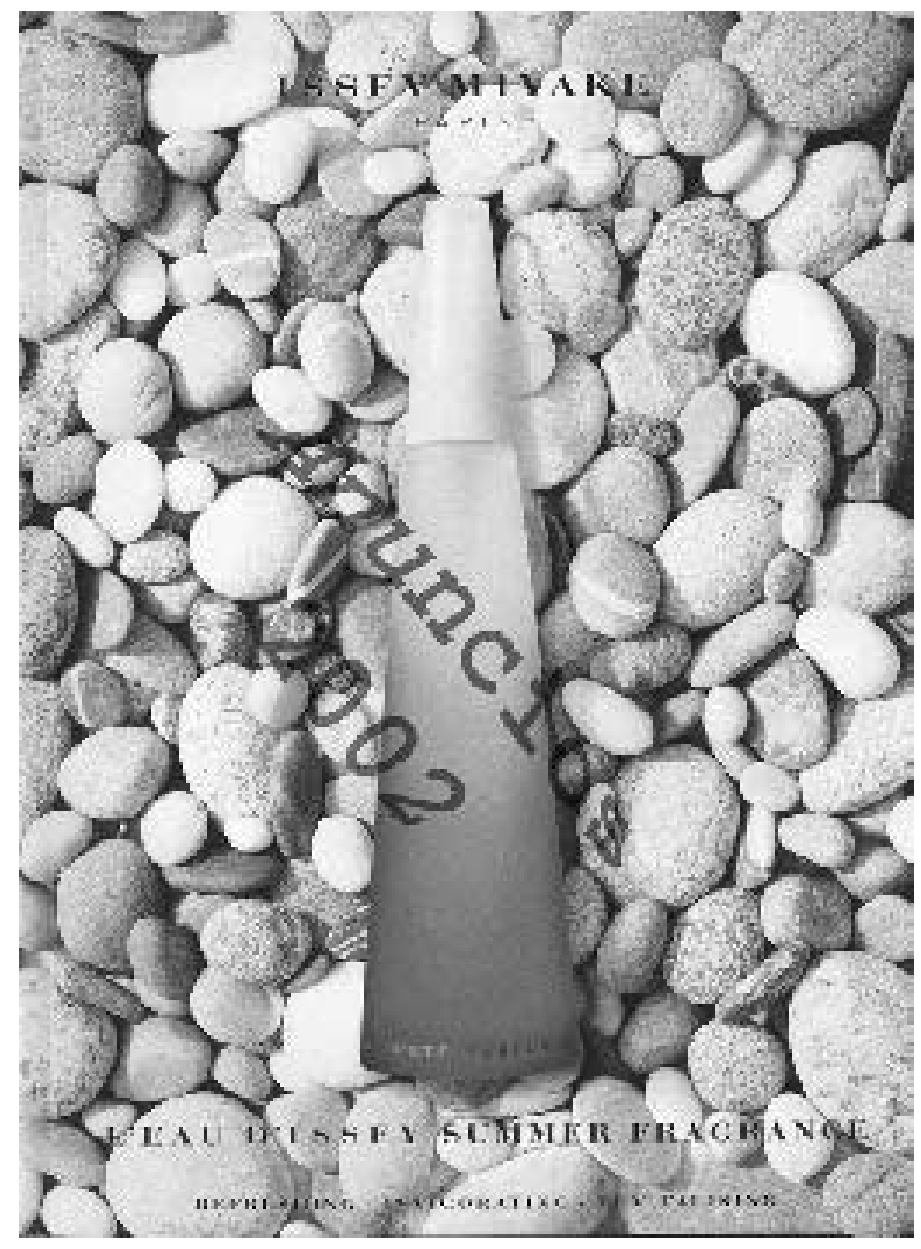

Metáfora convencional: la identificación entre el agua y el perfume ha perdido su carácter metafórico. Prueba de ello es que existen expresiones lexicalizadas como, por ejemplo, "agua de perfume" (eau de parfum) o "agua de colonia" (eau de toilette). 


\section{[5] LOS RELOJES MASCULINO Y FEMENINO SON UN HOMBRE Y UNA MUJER:}

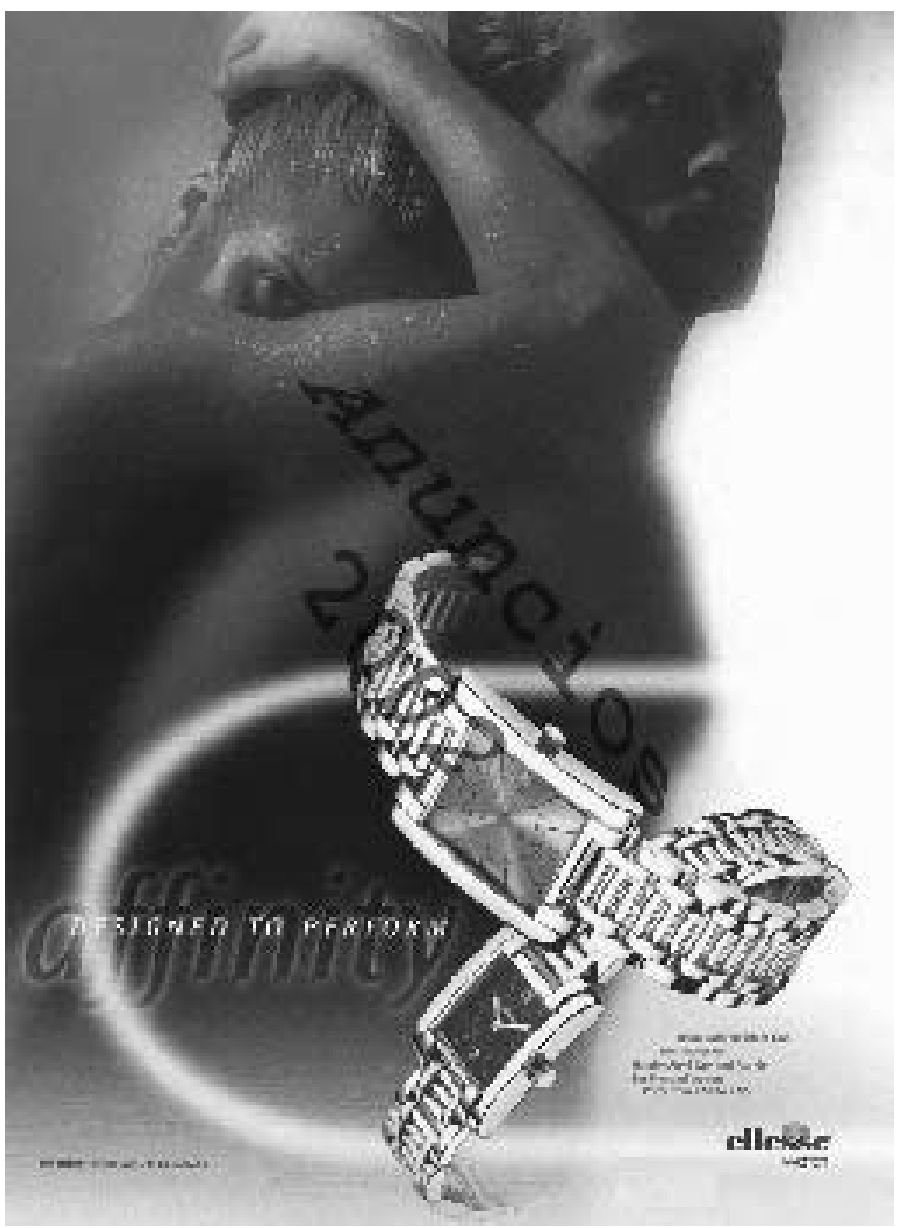

Metáfora basada en una similitud: con frecuencia se identifica el "sexo" del usuario con el producto anunciado: convencionalización que se observa en expresiones tales como "reloj de caballero" o "reloj de señora". 
[6] EL MÓVIL ES UN REY:

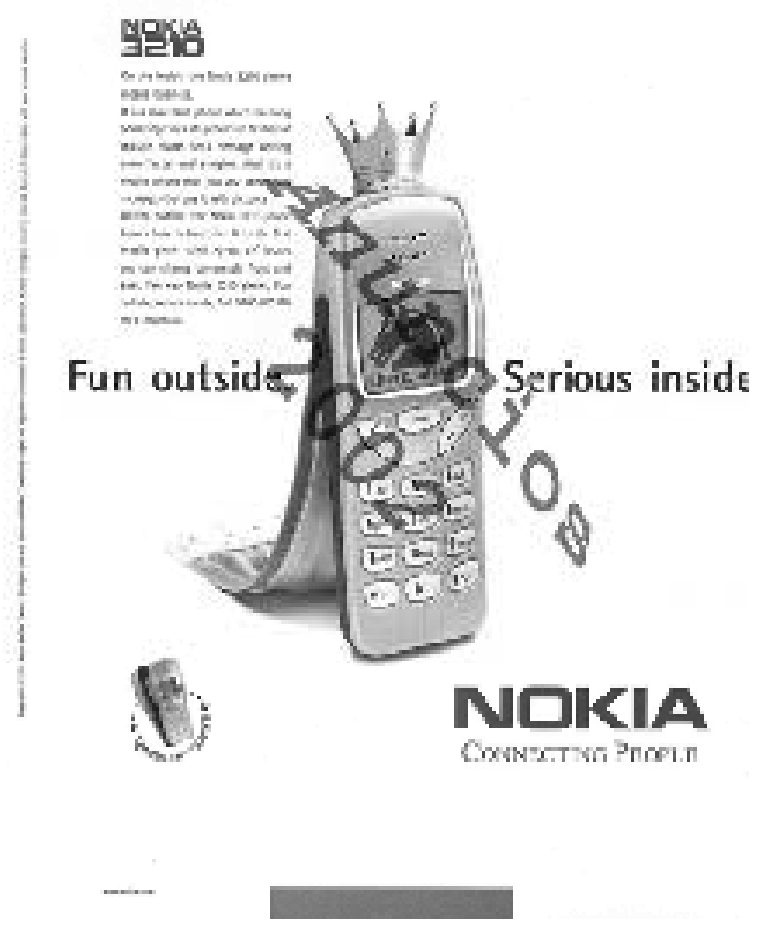

Metáfora creadora de similitud: la identificación de "un móvil" con "un rey" no obedece a la existencia de una semejanza previa a la creación de la metáfora, sino posterior a la misma ("exterior divertido, interior serio").

3. La metáfora es un elemento conceptual y la expresión metafórica publicitaria refleja dicha conceptualización en un nivel verbal, no-verbal o híbrido (Forceville, 1996, 2002; Velasco Sacristán, 2002).

En el caso concreto de la publicidad impresa se puede hablar de tres tipos diferentes de codificación o expresión metafórica: verbal, no-verbal o híbrida. El último tipo se divide a su vez en varios subtipos dependiendo de que los códigos que integren la metáfora y el orden en que se empleen (imagen + texto; texto + imagen, etc.) para interpretar la metáfora. Así, por ejemplo, podemos hablar de una metáfora "verbo-pictórica" cuando se trata de una metáfora que se materializa primero en un nivel verbal en algún elemento del anuncio (i.e. cuerpo de texto) y después en un nivel visual (i.e. ilustración) (Velasco Sacristán, 2002: 511). 
EJEMPLOS:

[7] EL PERFUME ES UN PEZ: Codificación pictórica:

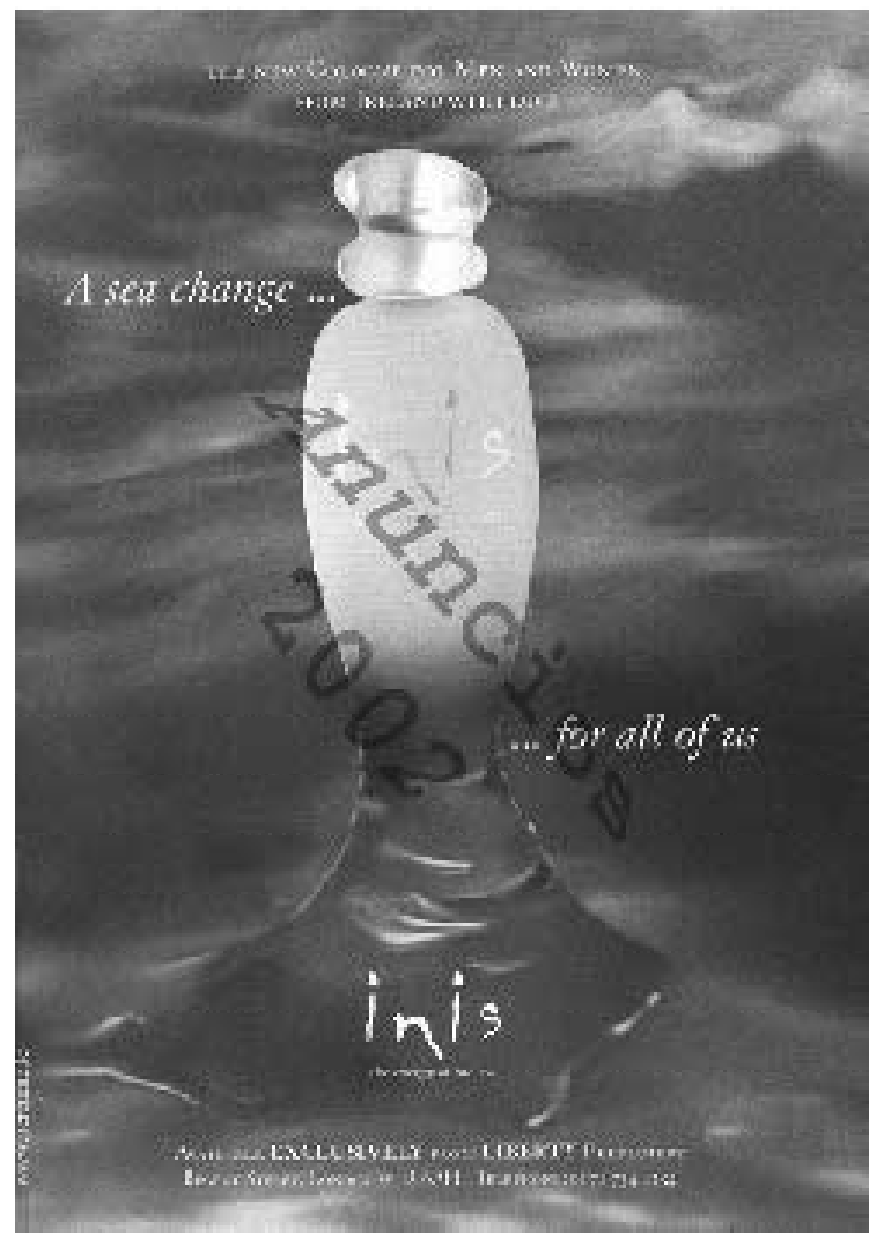

Odisea, $n^{\circ} \quad 4,2003$ 
[8] LA COLECCIÓN DE MAQUILLAJE ES LENGUAJE: Codificación verbal.

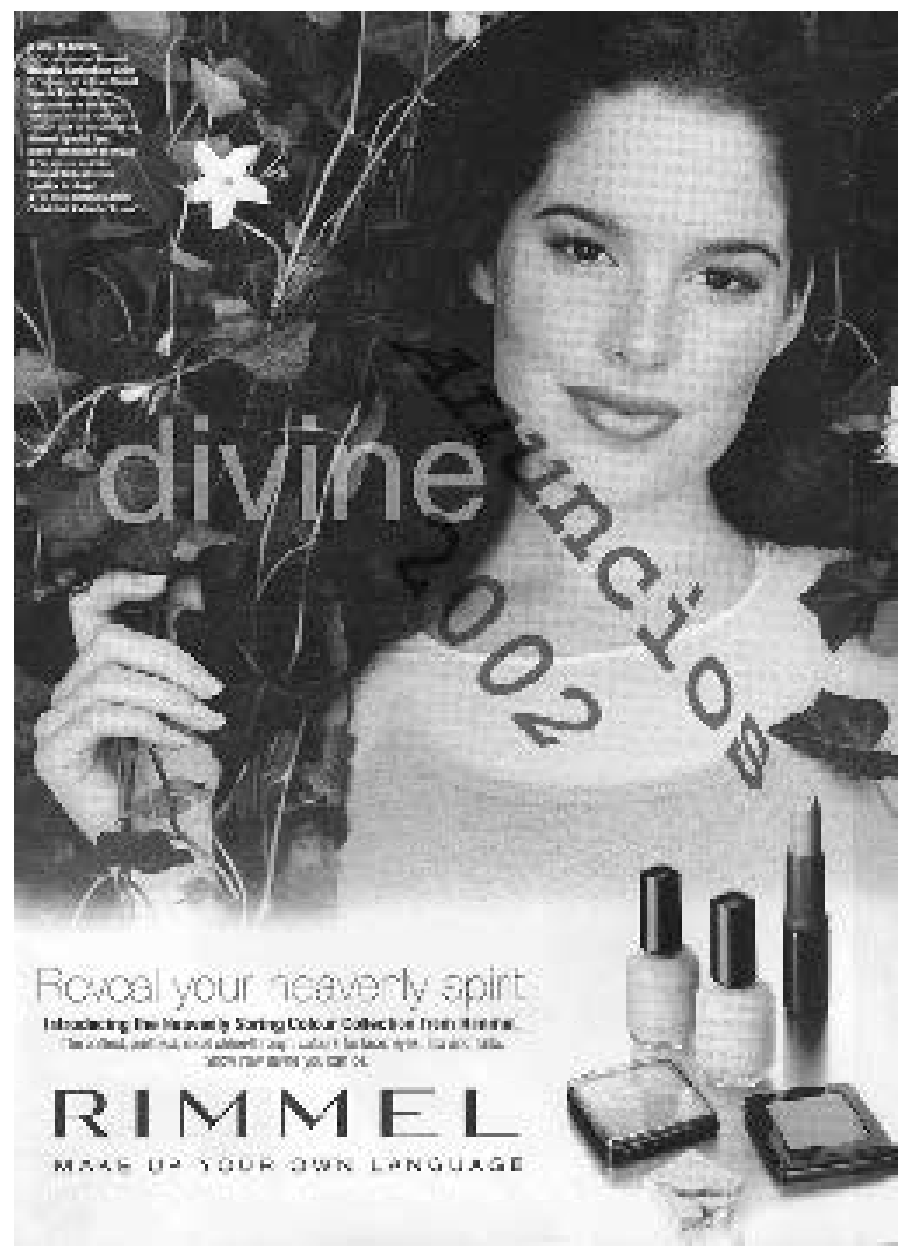


[9] LOS SERVICIOS FINANCIEROS SON IGUALDAD: Codificación pictórico-verbal.

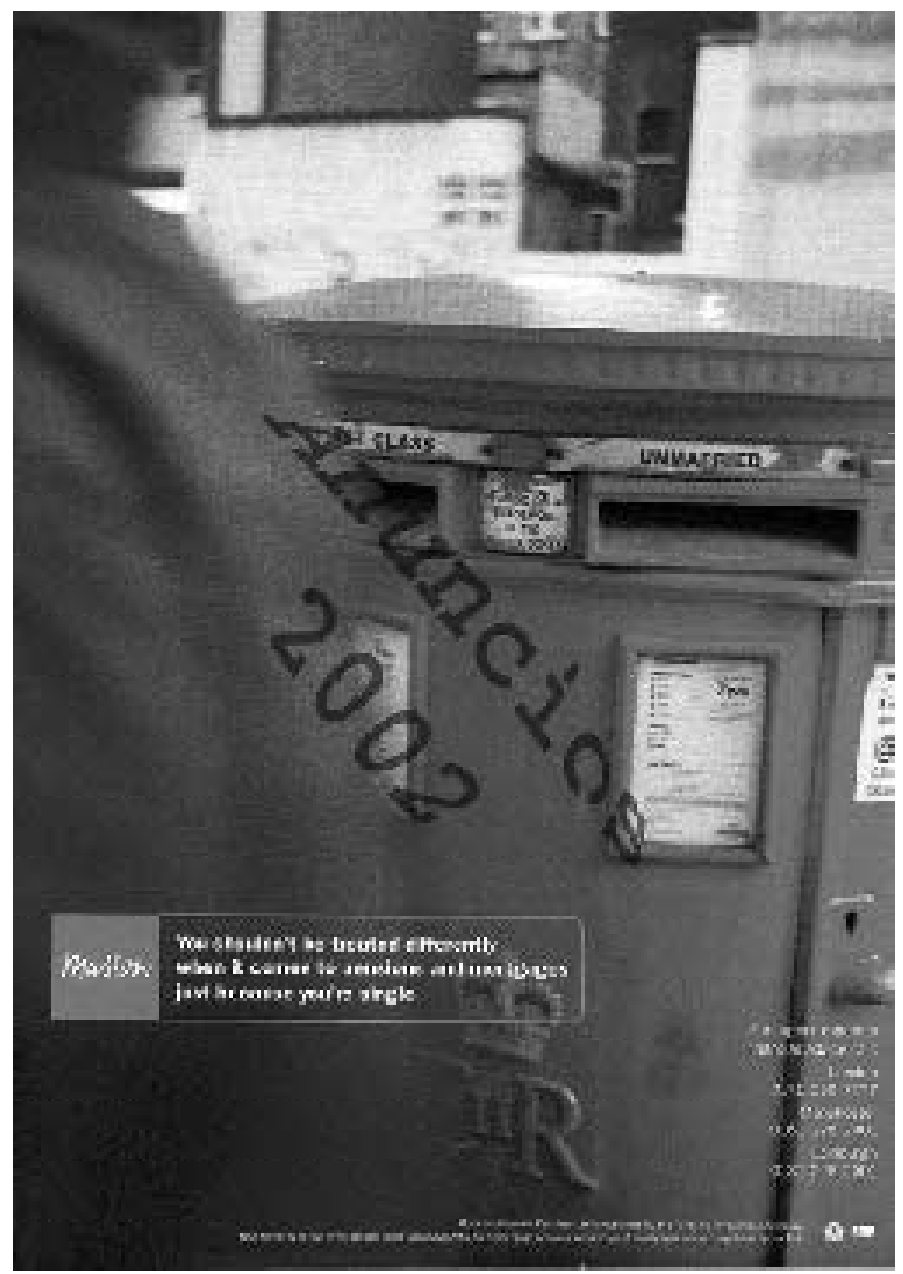


[10] LOS ZAPATOS SON ADICCIÓN: Codificación verbo-pictórica.

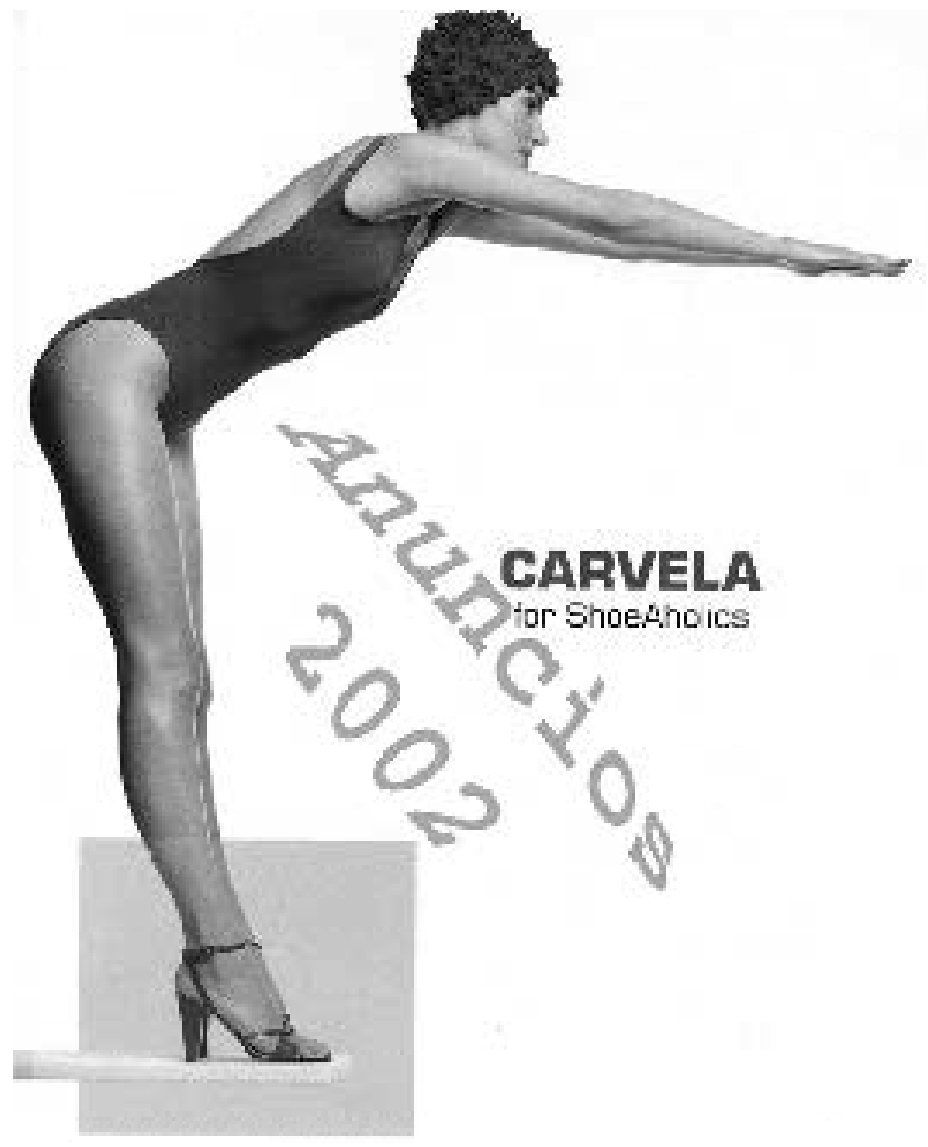

4. Entre los dos elementos de la metáfora media una proyección conceptual o mapping conforme al cual se transfieren sólo ciertas propiedades del segundo elemento al primero. Los anunciantes suelen aprovechar esta fase de proyección conceptual, mediante la selección, manipulación o creación de rasgos y propiedades ad hoc para introducir ideología sensual, hedonista, capitalista, etc. que combina o alterna con la atención a otros aspectos objetivos del producto para así crear una predisposición objetiva hacia el producto o servicio anunciado. 
EJEMPLOS:

[11] EL CAFÉ ES DESEO: Ideología hedonista.

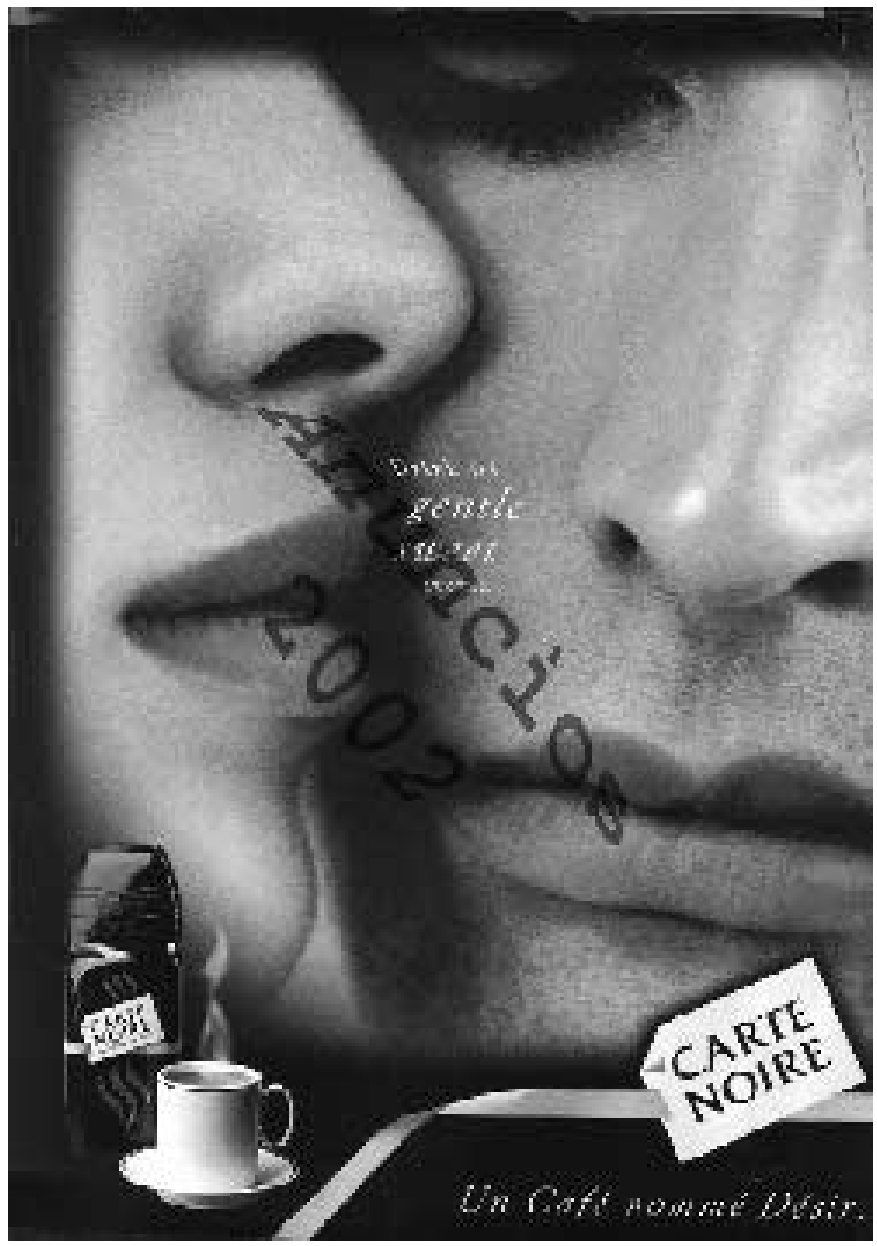


[12] LA BARRITA DE CHOCOLATE ES PLACER: Ideología sensual.

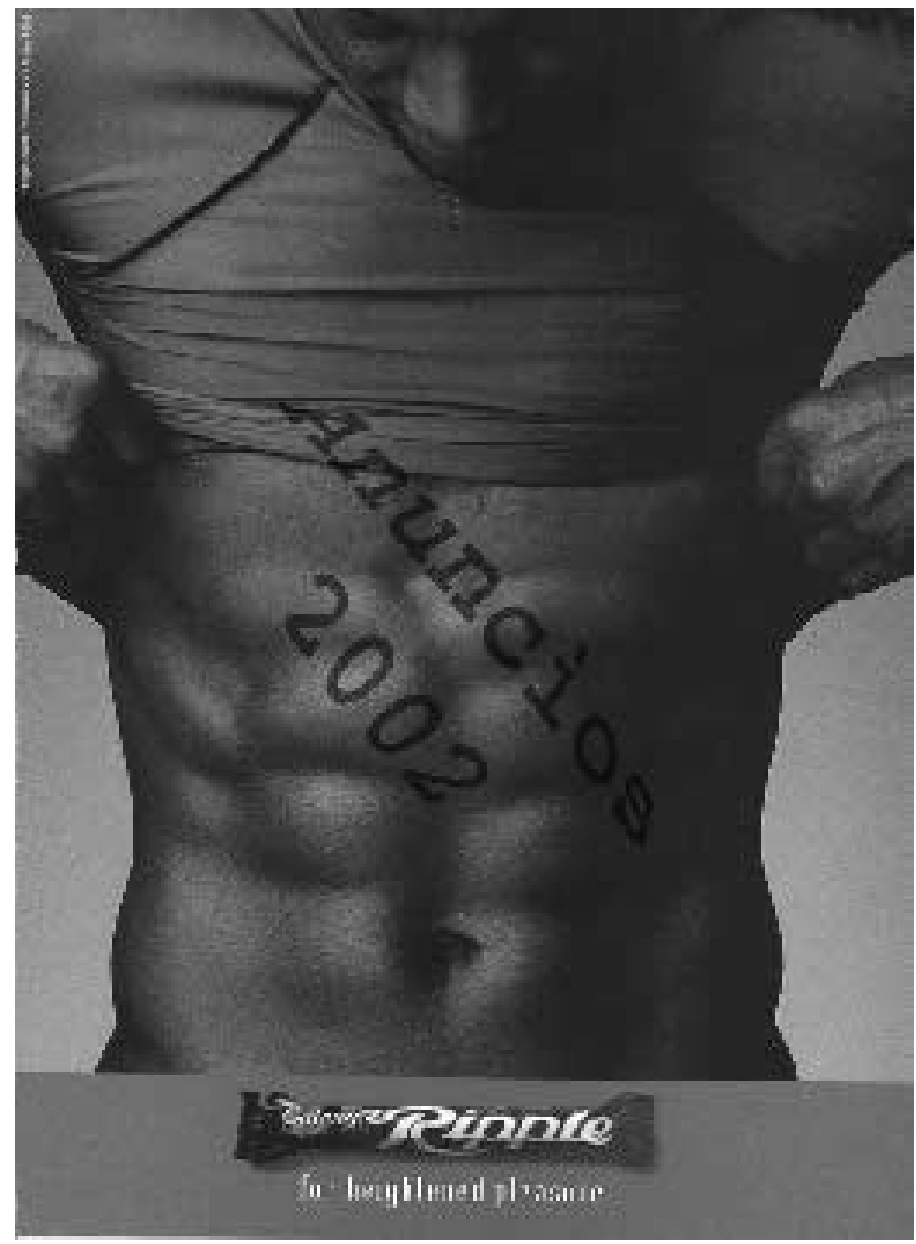

Todas estas características son cruciales para entender la formación de un tipo especial de metáforas publicitarias, las metáforas de género, de forma especial la última característica puesto que es el potencial ideológico de la metáfora publicitaria el que justifica su contribución a mantener el sistema asimétrico del género, convirtiéndose entonces en "metáforas publicitarias de género".

\section{LAS METÁFORAS PUBLICITARIAS DE GÉNERO}

El término "metáfora de género" es, como vimos en la introducción, una acuñación de Fuertes Olivera, (1999) que designa a aquella metáfora que crea y refleja una relación de discriminación por razón de sexo. 
La metáfora es, como venimos señalando, un fenómeno heurístico que constituye un ejemplo claro de la motivación del signo lingüístico, por lo que los hablantes extendemos el significado de dicho signo tanto para reflejar nuestras experiencias directas como nuestras visiones culturales del mundo que nos rodea. Es decir, conceptualizamos según lo que dicen, por un lado, nuestros sentidos y, por otro lado, nuestras tradiciones ${ }^{6}$. A raíz de esta doble posibilidad de conceptualización surgen dos tipos de metáforas de género: las metáforas universales de género y las metáforas culturales de género. A estos tipos hay que añadir además en el discurso publicitario el género metafórico que permite la sexualización de los inanimados.

\section{a. Las metáforas universales de género}

Son metáforas universales aquellas formadas a partir de las características comunes que comparten los seres humanos. Así, las metáforas espaciales u orientacionales nos indican, por ejemplo, cómo relacionar unos conceptos metafóricamente con otros según nuestra experiencia espacial. Según Lakoff y Johnson estas metáforas son las siguientes: "up-down" (arriba-abajo), "in-out" (dentro-fuera), "front-back" (adelante-atrás), "deepshallow" (profundo-superficial) y "central-peripheral" (central-periférico) (1980: 14-21). A estas categorías se pueden añadir otras también de denotación espacial, como por ejemplo: "primero-segundo", "grande pequeño", "horizontal-vertical”, etc. (Velasco Sacristán, 2002: 464). El primero de estos conceptos suele ser, por lo general, más positivo que el segundo. Algo obvio para el primer ejemplo en que debido a la ley de la gravedad conceptualizamos como "arriba" lo que es positivo mientras que lo que conceptualizamos como "abajo" es negativo. Hecho que se observa en expresiones metafóricas de variantes idiomáticas como, por ejemplo, "la cúpula del poder", "su alteza", "las capas altas de la sociedad", etc. En cuanto a "primero-segundo", una serie de binomios reservan la primera posición para el más poderoso (i.e. "blanco-negro", etc.). La espacialización de orden, tamaño, ubicación juega así un importante papel a la hora de conceptualizar relaciones sociales.

En el tema que nos ocupa este tipo de metáforas espaciales de tipo universal suelen presentar al hombre/mujer como persona poderosa, que está encima, en primer lugar, etc. y a la mujer/hombre como persona inferior, que está debajo, en segundo lugar, etc. produciéndose así la discriminación del hombre o la mujer por razón de sexo. Estas metáforas espaciales se convierten entonces en lo que nosotros denominamos "metáforas universales de género", que son aquellas que se emplean para marcar el espacio sociocultural, político y económico que está vetado al hombre o a la mujer por razón de sexo (Velasco Sacristán y Fuertes Olivera, 2001; Velasco Sacristán, 2002: 465).

\footnotetext{
${ }^{6}$ Existen diversas opiniones sobre si el proceso cognitivo de los comportamientos comunicativos es innato o surge por aprendizaje. La postura más acertada parece ser la conciliadora, es decir, la que defiende que los comportamientos iguales o semejantes en culturas diferentes depende sólo inicialmente de la experiencia común a todos los seres humanos, y son, por tanto, transculturales (González Martín, 1996: $255)$.
}

Odisea, $n^{\circ} 4,2003$ 


\section{EJEMPLOS:}

[13] LA MUJER ES UNA PERSONA SECUNDARIA: Metáfora orientacional que pone de relieve el dominio del espacio masculino sobre el femenino, con lo que se relega a las mujeres a un segundo plano (en la imagen en el fondo, a menor tamaño)

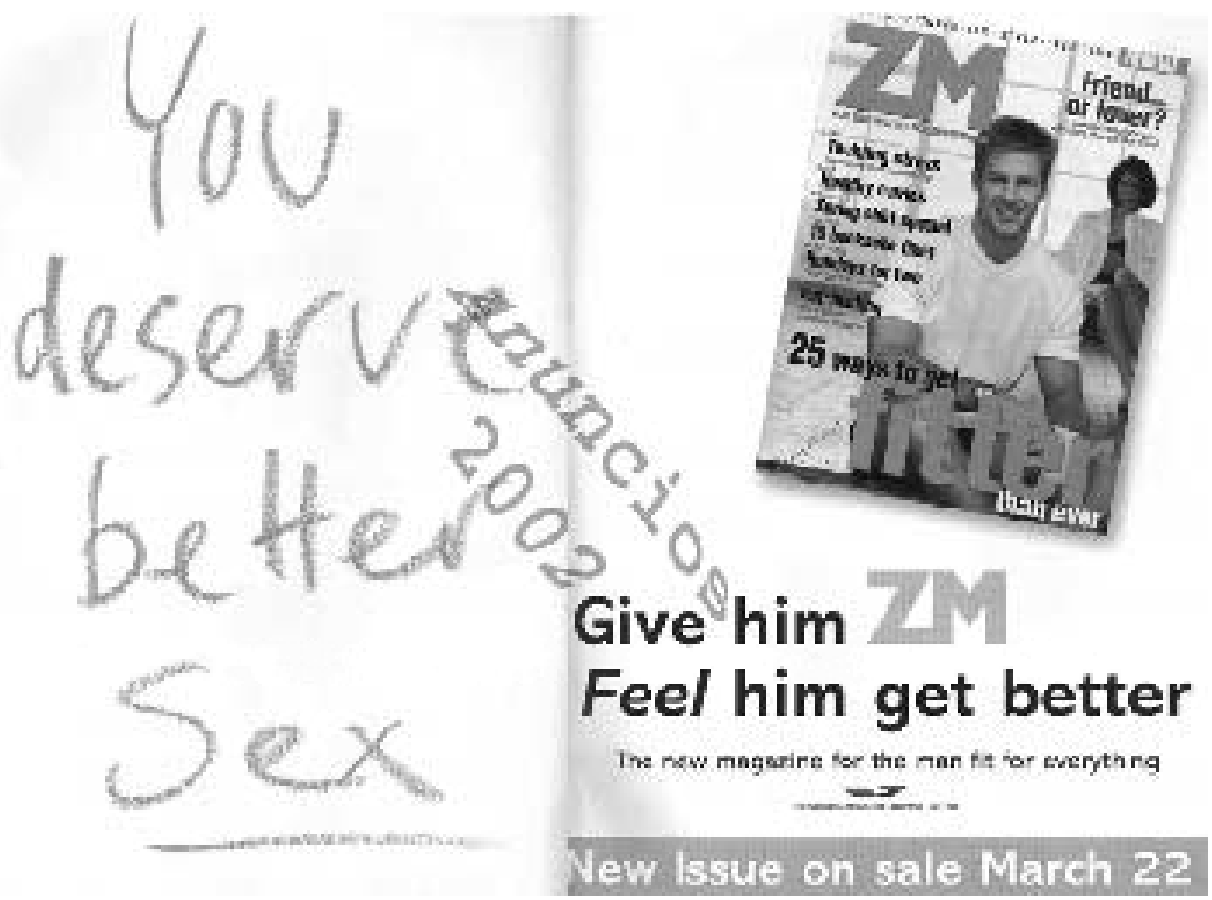


[14] LOS HOMBRES SON PERSONAS SECUNDARIAS: Metáfora orientacional que pone de relieve el dominio del espacio femenino sobre el masculino, con lo que se relega a los hombres a un segundo plano (en la imagen aparecen en el fondo, a menor tamaño).

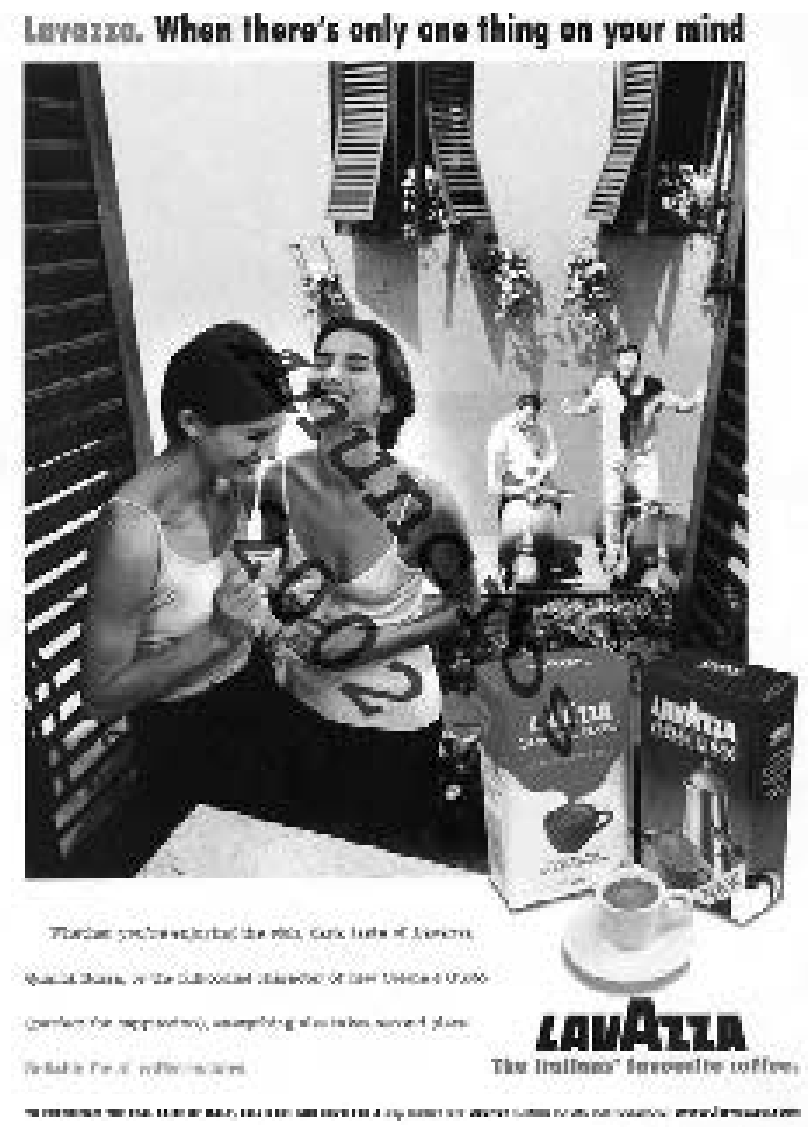

Además del empleo pernicioso de la localización universal de espacio, que resulta relativamente discriminatoria encontramos un uso más agravante de estas metáforas orientacionales de género cuando se emplean en sociedades patriarcales para transmitir una androginia social y representar la hombre como ser superior, poderoso y fuerte frente a la mujer (Mey, 1984: 278 y Fuertes Olivera, 1992: 85; 1999: 6), lo que parece confirmar que las metáforas universales de género se mueven a lo largo de un continuo metafórico en cuyo extremo opuesto se encuentran las metáforas culturales de género, hacia las que se van aproximando, iniciando así un "proceso de transculturización” por el que pierden parte de su universalidad inicial y adquieren naturaleza local. Estas metáforas universales de género se convierten en metáforas culturales de género propiamente dichas cuando 
reflejan valores asimétricos de género propios de una sociedad determinada, casi siempre por influencia de los estereotipos de género ${ }^{7}$.

\section{b. Las metáforas culturales de género}

Las metáforas culturales son aquellas que reflejan valores propios de una sociedad determinada. En este sentido se entiende el concepto de "cultura" en su acepción más amplia, que engloba valores religiosos, mitos, cuentos, creencias populares, artes escénicas, arquitectura, etc. (Fuertes Olivera, 1999)-

Estas metáforas cuando reflejan una discriminación por razón de sexo, en su mayor parte por influencia de los estereotipos de género pueden considerarse ejemplos de sexismo y devenir en lo que denominamos "metáforas culturales de género" que son aquellas que reproducen, lanzan y afianzan unos modelos discriminatorios para uno de los dos sexos (Velasco Sacristán y Fuertes Olivera, 2001; Velasco Sacristán, 2002: 467). Por lo general, este tipo de metáforas se apoya en observaciones del mundo real, especialmente el "mundo de los animales y de sus comportamientos, en nuestras tradiciones culturales, especialmente en los mitos literarios, en nuestras funciones corporales y en nuestras necesidades físicas (...) (Fuertes Olivera, 1999: 17), las metáforas culturales se emplean, por consiguiente, tanto en la descripción metafórica de los hombres como de las mujeres.

\footnotetext{
7 Los estereotipos de género son "a generalised and relatively fixed image of a person or persons belonging to a particular group. This image is formed by isolating or exaggerating certain features physical, mental, cultural, occupational, personal and so on- which seem to characterise the group" (Pauwels, 1998: 97).
} 


\section{EJEMPLOS:}

[15] LA LENCERÍA ES UNA MUJER: Metáfora conceptual basada en el estereotipo de la mujer como "objeto sexual".

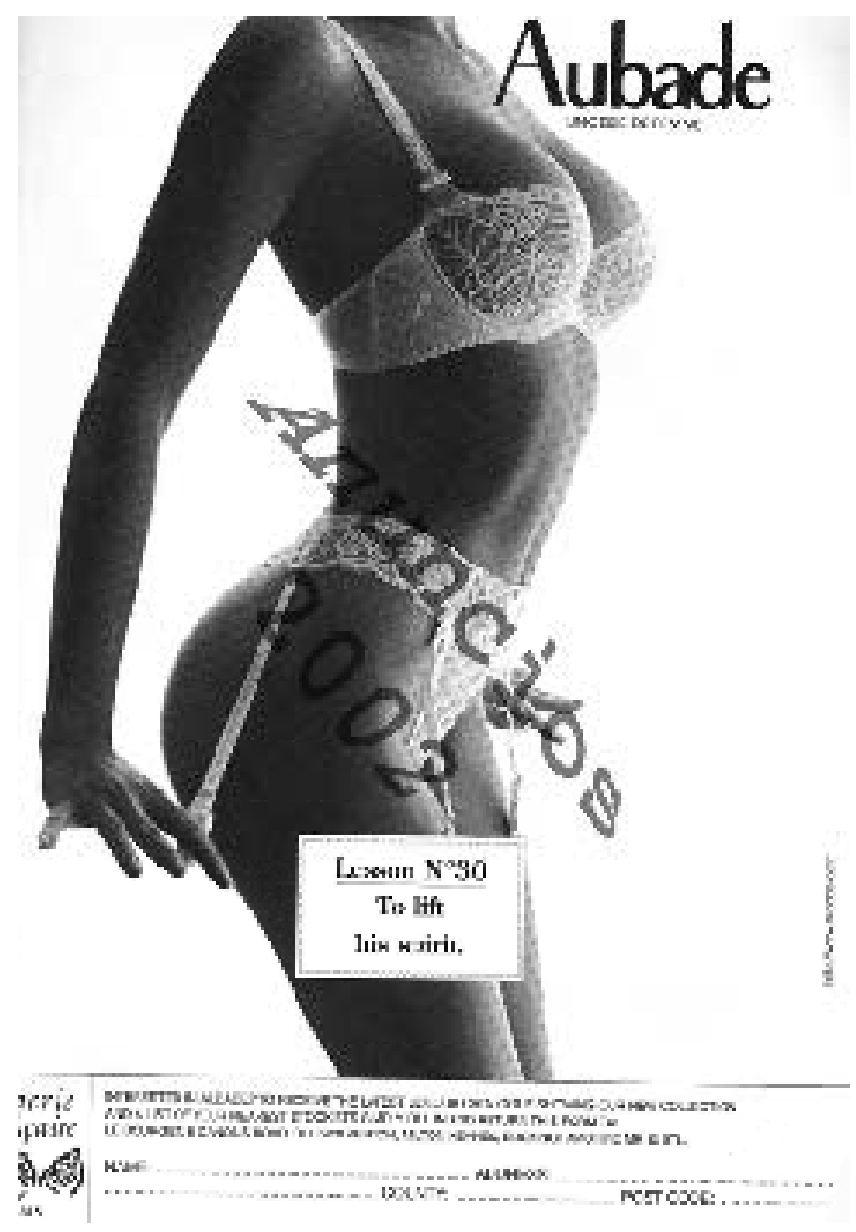


[16] EL COCHE ES UNA MUJER CON BUEN TIPO: Metáfora conceptual basada en el estereotipo de la mujer como "apariencia física".

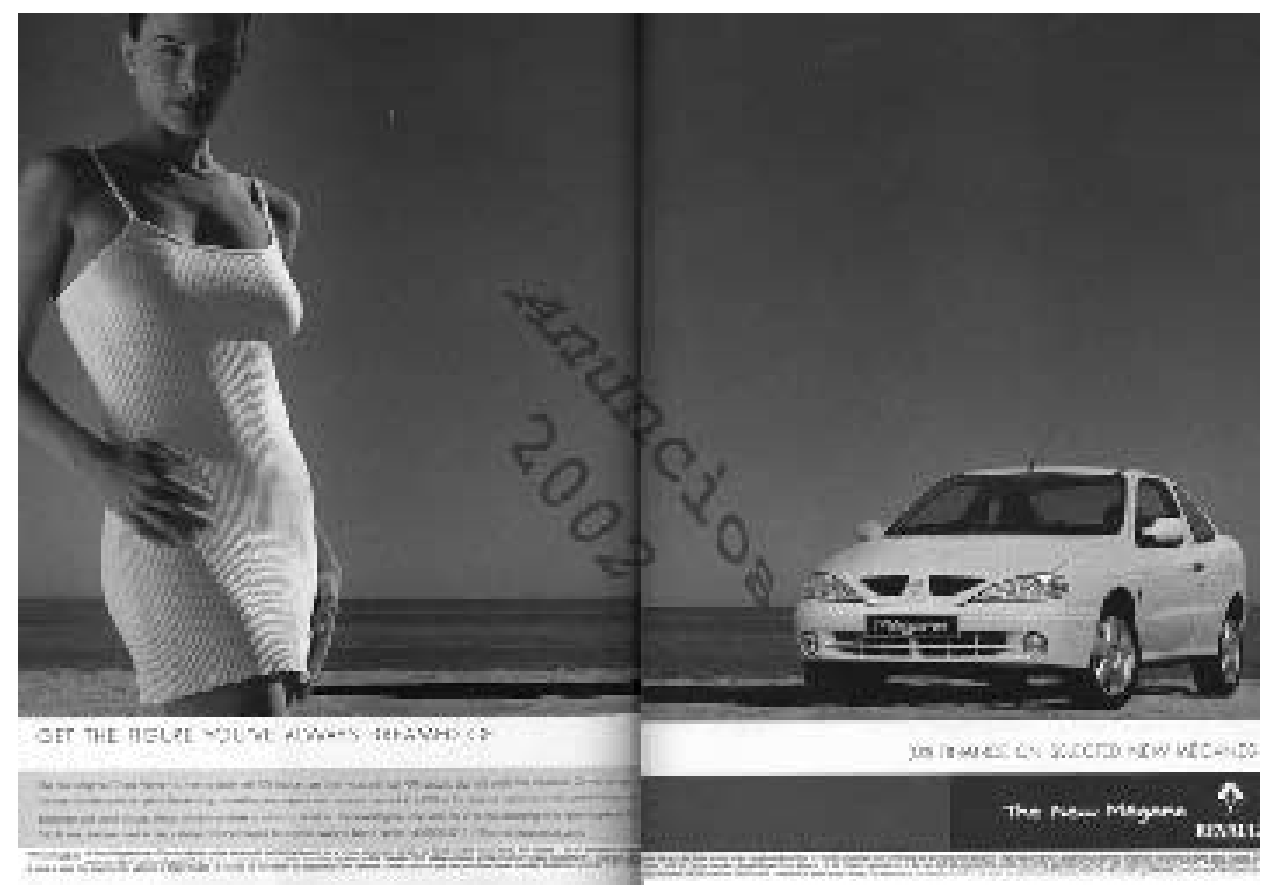


[17] LA MASCARILLA ES UN HOMBRE: Metáfora conceptual basada en el estereotipo del hombre como "objeto sexual".

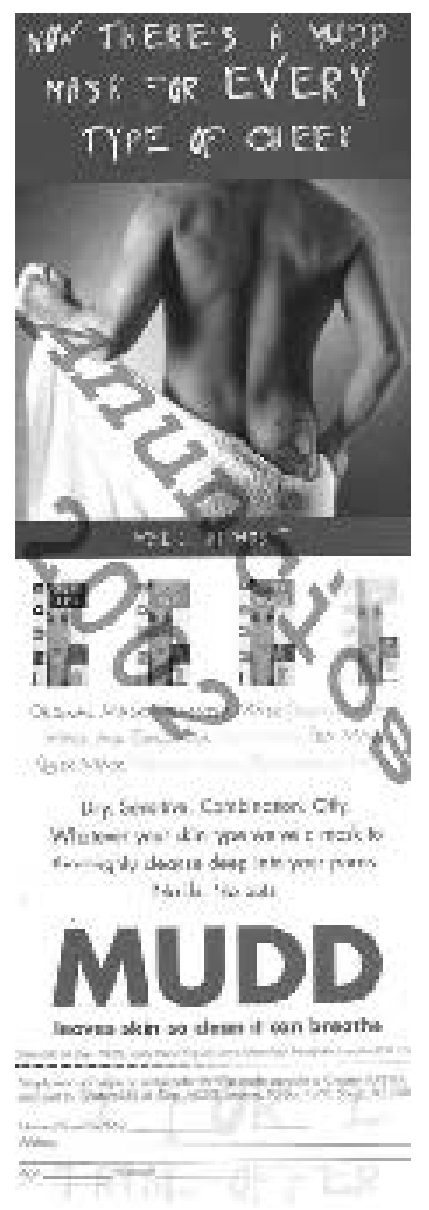

Este tipo de metáforas en la publicidad se suelen emplear con frecuencia para equiparar la posesión de la mujer con el producto o servicio anunciado (i.e. coche, perfume, bebida alcohólica, etc.), con lo que reflejan una visión androcéntrica del género.

(d)El género metafórico

El género metafórico surge por extensión a los inanimados del comportamiento sexual humano. El sexismo surge cuando se pronominaliza un inanimado que debería pronominalizarse con un pronombre neutro (Baron, 1971). En la publicidad este tipo de género tiene una gran incidencia, ya que, se tiende a personificar al producto anunciado y, a su vez, cosificar al consumidor. Es lo que se conoce como "la teoría de la metaforización antropomórfica de las mercancías” (Sánchez Corral, 1991: 182; 1997: 50-51). 
EJEMPLO de pronominalización verbal de origen metafórico:

[18] "Exquisite .... isn't she? ”: metáfora conceptual LA LENCERÍA FEMENINA ES UNA MUJER que se crea en base a la ambigüedad semántica de she que puede referirse a la lencería o a la mujer, que aparecen identificadas en la metáfora (codificación verbopictórica):

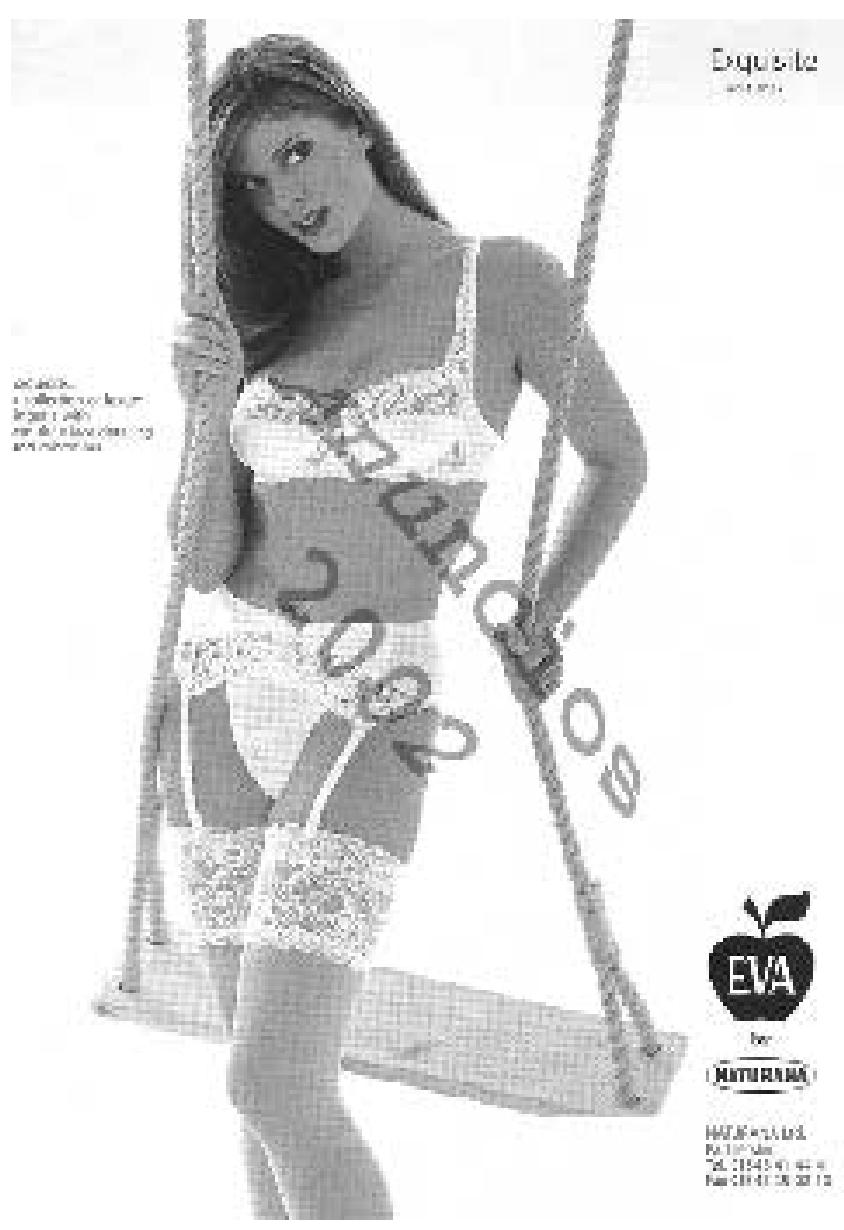

Además de esta pronominalización verbal, forma tradicional del género metafórico, se da en la publicidad la personificación a nivel pictórico o verbal. En la personificación pictórica aparece generalmente el producto o servicio personificado como persona, o bien sin determinar su sexo o bien como hombre o mujer (Velasco Sacristán, 2002: 472-473). 
EJEMPLOS:

[19] EL TAMPÓN ES UNA PERSONA

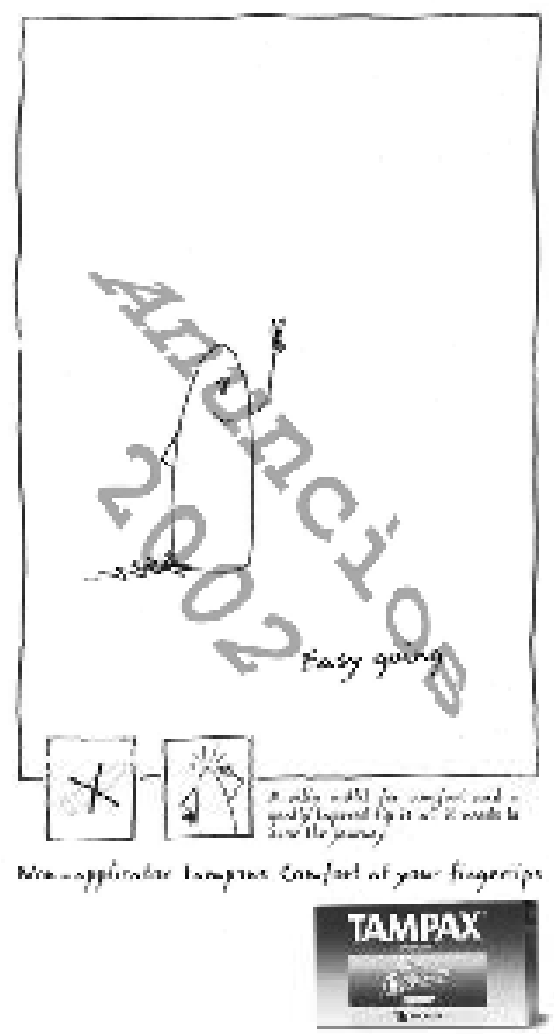

Odisea, $n^{\circ} \quad 4,2003$ 


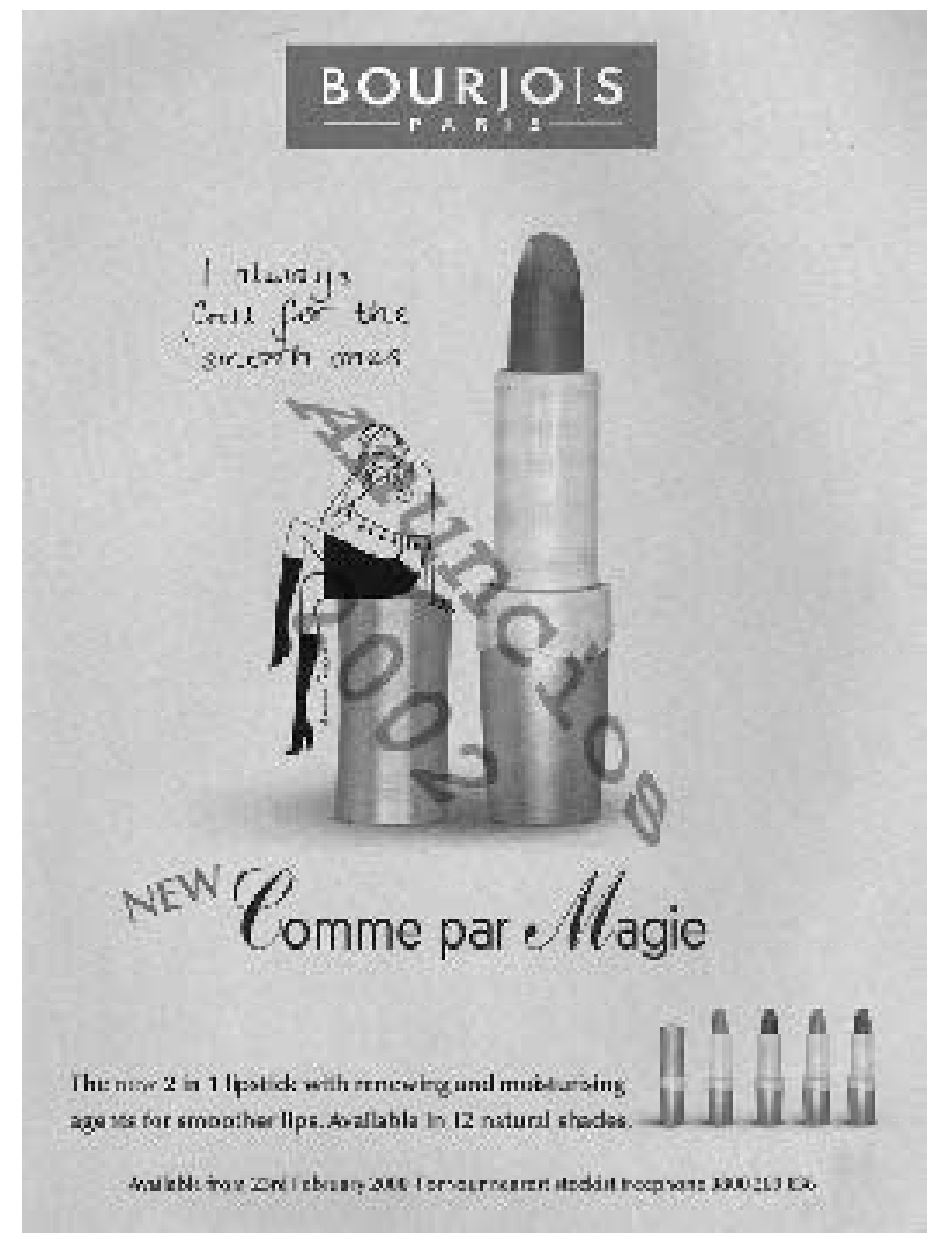

En lo que concierne a la personificación verbal encontramos al producto o servicio anunciado empleando el lenguaje verbal humano de las personas o bien frases típicamente usadas por mujeres u hombres. 


\section{EJEMPLOS:}

[21] LA BOTELLA DE VINO ES UNA PERSONA: uso de lenguaje verbal humano.

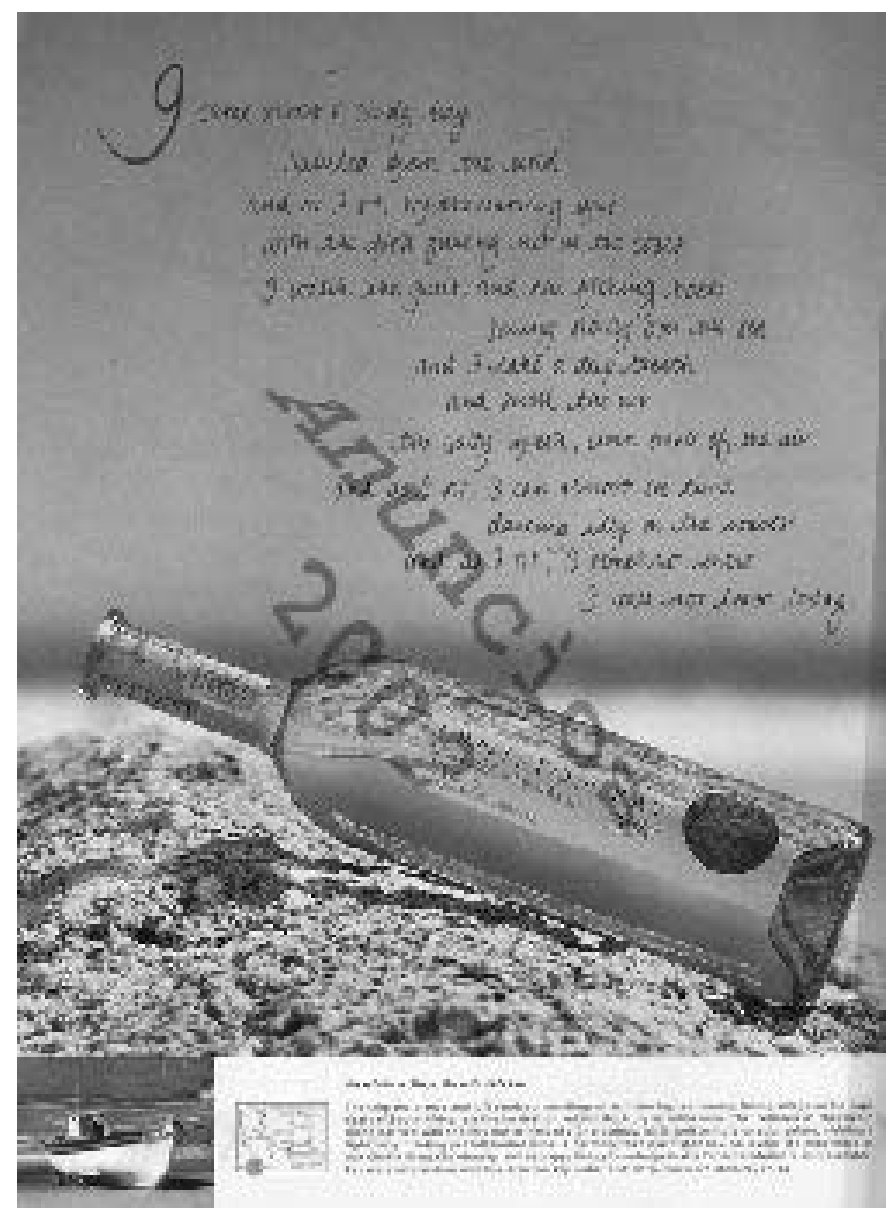


[22] EL QUESO BAJO EN CALORÍAS ES UNA MUJER: uso de lenguaje verbal típicamente femenino.

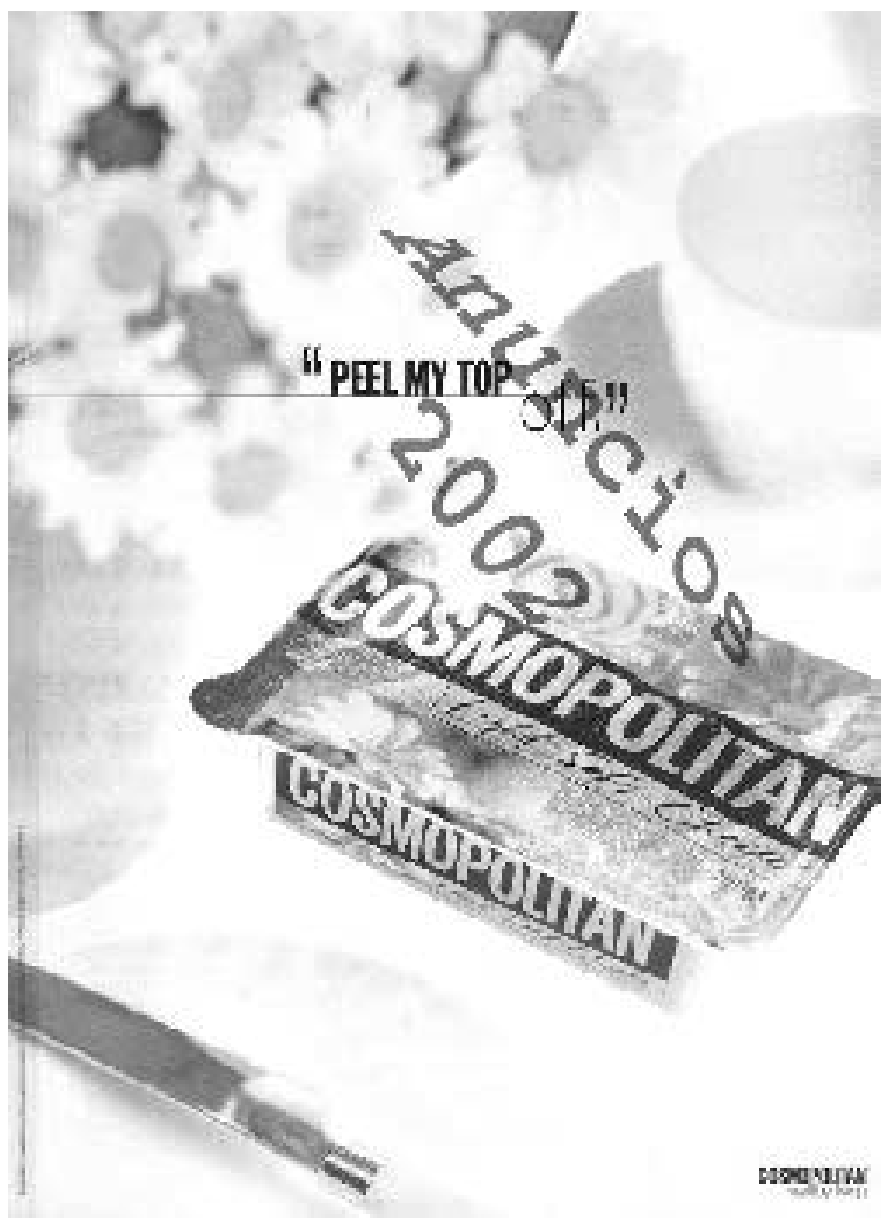

Este tipo de metáfora de género se emplea más para ensalzar al producto o servicio personificado que para discriminar al consumidor objetualizado, por lo que tiene en general un menor potencial sexista que las metáforas culturales de género y las metáforas universales de género. Podemos, por ello, señalar que estos tres tipos de metáforas de género, por su naturaleza propia, se presentan en un continuo metafórico de discriminación, cuyo extremo menos sexista es ocupado por el género metafórico, seguido de las metáforas universales de género, y finalmente las metáforas culturales de género, que ocupan el extremo más sexista.

Además de este potencial intrínseco de discriminación por razón de sexo, no hay que olvidar que, como señalábamos en la introducción, la interpretación de las metáforas de 
género varía de unos receptores a otros, por lo que no todas las metáforas de género son sexistas. En efecto una misma metáfora de género puede ser considerada sexista por unos receptores mientras que otros ignoran el componente discriminatorio de las mismas. Habrá que convenir, no obstante, que cuando una colectividad representativa de receptores interprete una metáfora de género como sexista estaremos efectivamente ante un recurso de discriminación por razón de sexo. Es decir, el sexismo de la metáfora de género no radica en la metáfora misma, sino en el uso que se hace de ella.

\section{CONCLUSIONES}

El empleo de recursos semióticos como las metáforas publicitarias de género en la publicidad de revistas femeninas como British Cosmopolitan prueba la existencia de un tipo de sexismo sutil, el sexismo semiótico, que opera a nivel implícito, presentando formas no exclusivamente verbales.

Los tres tipos de metáforas publicitarias de género identificadas en este artículo -las metáforas universales de género, las metáforas culturales de género y el género metafóricono tienen capacidad por si mismas de ser discriminatorias. Adquieren, sin embargo, naturaleza sexista cuando su uso propicia la interpretación discriminatoria por parte de una colectividad representativa de receptores. Su naturaleza intrínseca parece evidenciar, no obstante, que estos tres tipos de metáforas se mueven en un continuo metáforico de sexismo, apareciendo el género metafórico en el extremo menos sexista, las metáforas universales de género en la posición intermedia y las metáforas culturales de género en el extremo más sexista.

El uso mayoritario de metáforas de género que discriminan a la mujer en British Cosmopolitan prueba una actitud de desigualdad hacia la condición femenina que viene a constatar que son, en efecto, aún hondas las raíces de la visión androcéntrica y patriarcal de la sociedad que refleja la publicidad de revistas femeninas de marcada ideología de liberación sexual como British Cosmopolitan.

La identificación y denuncia de estas metáforas por parte de los receptores de este tipo de revistas ha de servir, tal y como propone el análisis crítico del discurso, para elevar el estado de conciencia de la sociedad contemporánea y alertar a los organismos encargados de luchar contra el sexismo en la publicidad ("ASA"-Advertising Standards Associationpara la publicidad británica). Nuestra aportación particular aquí tiene como finalidad específica hacer avanzar la reflexión teórica hacia esta conciencia colectiva de los receptores de las revistas femeninas que ha de constituir el primer paso hacia una propuesta institucional de subversión de los valores asimétricos de género establecidos por la publicidad de revistas femeninas como British Cosmopolitan. 


\section{REFERENCIAS BIBLIOGRÁFICAS:}

Aarts, J. M y J. P. CAlbert 1979. Metaphor and Non-Metaphor: The Semantics of Adjective -Noun Combinations. Tübingen: Niemeyer.

BARON, N. S. 1971. “A Reanalysis of English Grammatical Gender”. Lingua 27: 113140.

Barros García, P. 1977. “La lengua y la publicidad”. Español Actual 33 (Junio 1977). Madrid: Ofines: 1-27. . 1978. "El lenguaje de la publicidad en la televisión”. Español Actual 38 (enero-diciembre 1978). Madrid: Ofines: 9-17.

Barthes, R. 1957/80. Mythologies. London: Paladin.

1964. "Rhetórique de 1' image". Communications, 4: 40-51.

1967. Elements of Semiology. London: Cape.

Belkaoui, A. y J. Belkaoui 1976. “A comparative analysis of the roles portrayed by women in print advertisements: 1958, 1970, 1972'. Journal of Marketing Research 13 (mayo): 168-172.

Berger, J. 1972. Ways of Seeing. Baltimore: Penguin Books.

Billingham, P. 2001. Sensing the City through Television: Urban Identities in Fictional Drama. Bristol: Intellect.

Boers, F. 1996. Spatial Prepositions and Metaphor: A Cognitive-Semantic Journey along the UP-DOWN and the FRONT-BACK Dimensions. Tübingen, Germany: Gunter Narr.

Bonsiepe, G. 1969 Retórica y Publicidad. Bremond, Universidad de Chile: Claude (policopiado).

Bousoño, C. 1970. Teoría de la Expresión Poética. Madrid: Gredos.

BRISTOw, J. 1997. Sexuality. London: Routledge.

British Cosmopolitan (noviembre 2002).

Brooker, P. 1999. A Concise Glossary of Cultural Theory. London: Arnold.

Brown, M. A. 1997, “A comparison between adult and children's advertising on television”. (Documento de Internet disponible en http://www.wcsu.ctstateu.edu/ $\sim$ mccarney/acad/brown.html).

Bruthiaux, P. 1996. "The discourse of classified advertising: Exploring the nature of linguistic simplicity". Oxford Studies in Sociolinguistics, Oxford and New York: O.U.P.

ButLer, J. 1990. Gender Trouble: Feminism and the Subversion of Identity. London: Routledge. 
Campos Pardillos, M. A. 1994. Mecanismos de adaptación e individualización del mensaje publicitario en lengua inglesa. Alicante: Departamento de Filología Inglesa. Tesis Doctoral inédita.

Cardona, D. y R. F. Berasarte 1972. Lingüistica de la Publicidad. El Idioma Español y la Publicidad. Azanca: Madrid.

Castagnotto, M. 1970. Semantica della pubblicità. Roma: Silva.

Chandler, D. 1994. “Semiotics for beginners". (Documento de Internet disponible en http://www.aber.ac.uk/ dgc/semiotic.html).

Сhébat, J. C. у G. M. Henault 1974. "L'efficacité de l' image pubblicitaire". Communications et targages 22: 109-116.

Cohen, J. 1970. Estructura del Lenguaje Poético. Madrid: Gredos.

COOPER, R. 1984. "The avoidance of androcentric generics". International Journal of Sociology of Language, 50: 5-20.

Cook, G. 1992. The Discourse of Advertising. London and New York: Interface: Routledge.

Cosmopolitan Hispana (enero 2001).

Courtney, A. E. y Lockeretz, S. 1971 “A woman's place: An analysis of the roles portrayed by women in magazine advertisements". Journal of Marketing Research 13: $168-172$.

Craig, S. 1992. "The effect of television day part on gender portrayals in television commercials: A content analysis”. Sex Roles 26 (5-6): 197-211.

Di Sparti, A. 1975. "Linguaggio pubblicitario. Analisi lingüística di un corpus pubblicitario di sigarette americana”. Quaderni del Circolo.

DíAz PÉrez, F. J. 2000. “Sperber and Wilson’s relevance theory and its applicability to advertising discourse: Evidence from British press advertising”. Atlantis. Revista de la Asociación Española de Estudios Norteamericanos. XXII, 2 : 37-50.

Doyle, M. 1998. "Introduction to the A-Z of non-sexist language". The Feminist Critique of Language. A Reader. Ed. D. Cameron London and New York: Routledge. Reimpresión de un extracto de Doyle, M. 1995. The A-Z of Non-Sexist Language. London: Women's Press.

DufF, M. 1994. "Body of evidence: Studying women and advertising". Gender \& Utopia in Advertising. A Critical Reader. Eds. L. Manca y A. Manca. Lisle, Illinois: Procopian Press: 5- 29.

Durand, J. 1970. "Rhétoriques et image publicitaire". Communications, 15: 70-95.

Dyer, G. 1982. Advertising as Communication. London: Routledge.

Eco, U. 1976. Introducción al Estructuralismo. Madrid: Alianza Editorial. 
Press.

1978. Semiotics and the Philosophy of Language. London: MacMillan

Edwards, T. 1997. Men in the Mirror: Men's Fashion, Masculinity and Consumer Society. London: Cassell.

ESS European Subscription Service 1998. (Folleto publicitario).

FAirclough, N. 1989. Language and Power. London: Longman.

. 1992. Discourse and Social Change. London: Longman.

y Wodak. R. 1997. "Critical discourse analysis". Discourse Studies: A

Multidisciplinary Introduction, II: Discourse as Social Interaction. Ed. T. van Dijk. Thousand Oaks CA: Sage: 258-84.

Fasold, R., YAMADA, H.; RoBINSON, D. y BARISH, S. 1990. “The language planning effect of newspaper editorial policy: Gender differences". The Washington Post-language in Society 19: 521-539.

Feliu, E. 1984. Los Lenguajes de la Publicidad. Alicante: Universidad.

Ferraz Martínez, A. 1993. El Llenguaje de la Publicidad. Arco: Madrid.

Ferrer Rodríguez, E. 1994. El Lenguaje de la Publicidad. México: Tezontle, Fondo de Cultura Económica.

Forceville, C. 1996. Pictorial Metaphor in Advertising. London and New York: Routledge.

. 2002. "The identification of target and source in pictorial metaphors". Journal of Pragmatics 34: 1-14.

Foucault, M. 1984. "The history of sexuality". Volume one: The Will to Knowledge. London: Penguin ( $2^{\mathrm{a}}$ edición).

Fowler, R., Hodge, B. ; Kress, G. y Trew, T. 1979. Language and Control. Routledge: Kegan Paul.

Friedan, B. 1963. The Feminine Mystique. New York: W. W. Norton and Company.

Fuertes Olivera, P. A. 1992. Mujer, Lenguaje y Sociedad. Los Estereotipos de Género en Iinglés y en Español. Ayuntamiento de Alcalá de Henares: Madrid.

. 1999. Metáfora y Sexismo lingüístico. UNED: Medina del Campo, Valladolid. (Conferencia del curso 1998-1999).

. Velasco-Sacristán, M.; Samaniego-Fernández. E y Arribas-Baño, A. 2001 "Persuasion and advertising English: Metadiscourse in slogans and headlines". Journal of Pragmatics 33 (8): 1291-1307.

GAL, S. 1989. "Between speech and silence: The problematics of research on language and gender". Gender at the Crossroad of Knowledge: Feminist Anthropology in the Postmodern Era. Ed. M. DI LEORDARDo. Berkeley: University of California Press: 175-203. 
García Berrio, A. 1975. "Lingüística, Literariedad-poeticidad (Gramática, Pragmática, Texto)", 1616. Anuario de la Sociedad Española de Literatura General y Comparada II, 1980: 127-170.

García Meseguer, A. 1994. ¿Es sexista la lengua española? Una investigación sobre el género gramatical?. Paidós: Buenos Aires.

García Nieto, T. 2001. "Los programas femeninos, las revistas especializadas o las secciones específicas sobre la mujer. La mujer consumidora de prensa y televisión”. Congreso Internacional: Mujeres, Hombres y Medios de Comunicación. Valladolid: 12- 14 noviembre.

Gentner, D., Falkenhainer, B.; y Skorstad. J. 1989 “Metaphor: The good, the bad and the ugly". Theoretical Issues in Natural Language Processing. Ed. Y. Wilks. Hillsdale. NJ: Lawrence Erlbaum Associates.

GodDARD, A. 1998. The Language of Advertising. London and New York: Routledge.

GofFMAn, E. 1976. Gender Advertisements. London and Basingstoke: The Macmillan Press.

Gómez Moreno, J. D. 1993. "Especificidad del análisis de errores de traducción en la enseñanza del inglés empresarial”. Sevilla: Universidad. Tesis doctoral inédita.

GonzÁlez Martín, J. A. 1996. Teoría General de la Publicidad. Madrid: Fondo de Cultura Económica.

Harding, J. 1998. Sex Acts: Practices of Femininity and Masculinity. London: Sage.

HaRnARD, S. 1982. "Metaphor and mental duality”.. Language, Mind and Brain. Eds. T. Simon y R. Scholes. Hilldale, New Jersey: Erlbaum: 189-211.

Hermes, J. 1995. Reading Women's Magazines. Cambridge: Polite Press.

Hernando, L. 1970. El Lenguaje de la Publicidad.

Heywood, J. 1997. Language and Masculinity. Ed. S. Johnson y U. H. Meinhoff. Oxford. Blackwell.

Hodge, R. y Kress, G. 1993. Language as Ideology. London: Routledge. (2 edición).

HuBbard, R. C. 1994. "Sex and the selling of male fragrances". Gender \& Utopia in Advertising. A Critical Reader. Eds. L. Manca y A. Manca. Lisle, Illinois: Procopian Press: 111-131.

Huertas, F. 1967. El Lenguaje Publicitario.

IndurkhyA, B. 1992. Metaphor and Cognition: Studies in Cognitive Systems. Dordrecht, The Netherlands: Kluwer Academic Publishers.

JACKson, P, Stevenson, N; y BRooks, K. 2001. Making Sense of Men's Magazines. Cambridge: Polity Press.

Johnson, S. y MeInhoff, U. H. eds. 1997. Language and Masculinity. Oxford: Blackwell. 
Johnson, S. y Finlay, F. 1997. Language and Masculinity. Ed. F. L. Johnson y U. H. Meinhoff. Oxford: Blackwell.

Kendall, G. y Wickham , G. 1999. Using Foucault's Methods. London: Sage.

Killbourne, W. 1990. "Female stereotyping in advertising: An experiment on malefemale perceptions of leadership". Journalism Quarterly 67, 1: 25-31.

Kress, G. 1989. Linguistics Processes in Sociocultural Practice. Oxford University Press.

Kress, G. y Hodge, R. 1979. Language as Ideology. Routledge.

Lakoff, G. y Johnson. M. 1980. Metaphors we Live by. Chicago: The University of Chicago Press.

Lakoff, G. y Turner: M. 1989. More Than Cool Reason: A Field Guide to Poetic Metaphor. Chicago: Chicago University Press.

LEECH, G. N. 1966. English in Advertising: A Linguistic Study of Advertising in Great Britain. London: Longman.

LEFF, L. 1980. “TV ads reflect power of working women”. Wall Street Journal, 30 October: 25.

LeVere, J. 1974 "Portrayal of women in ads defended by top ad women". Editor and Publisher 8 (junio).

Leymore, V. 1975. Hidden Myth: Structure and Symbolism in Advertising. London: Heinemann.

Mac An GhaIL, M. 1996. Understanding Masculinities. Buckimgham: Open University Press.

MacCormac, E. R. 1985. A Cognitive Theory of Metaphor. Cambridge, Massachussets: M. I. T. Press.

Manca, L. y Manca, A. ed. 1994. Gender \& Utopia in Advertising. A Critical Reader, Lisle, Illinois: Procopian Press.

McGlone, M. 1996. "Conceptual metaphors and figurative language interpretation: Food for thought?". Journal of Memory and Language, 35: 544-565.

McQuarrie, E. F. y Mick, D. 1992. “On resonance: A critical pluralistic inquiry into advertising rhetoric". Journal of Consumer Research 19, 3: 180-197. (Documento disponible en Internet: http://scuish.scu.edu/SCU/Departm...ting/faculty/ mcqustuff/reson.55.htm).

Merquior, J. G. 1991. Foucault. London: Fontana Modern Masters.

Mewe Fernández, N. 1996. “Agresores y agredidos en la prensa escrita: Estereotipos clásicos y estereotipos emergentes en los discursos mediáticos". Actas del Congreso Internacional celebrado en la Universidad Complutense de Madrid en 1996. Ed. J. Garrido Medina. Madrid: Universidad Complutense: 290-297. 
MEY, J. 1984. “Sex and language revisited: Can women's language change the world?". Journal of Pragmatics 8: 261-283.

.1985. "Whose language? A study". Linguistic Pragmatics. John Benjamins Publishing Company: Amsterdam/Philadelphia.

Meyerhoff, M. 1984. A Study of Sexist and Non-sexist Language in Written New Zealand English. Project paper at the Victoria University of Wellington, New Zealand.

Moragas, M. de 1980. Semiótica y Cmunicación de Masas. Barcelona: Península. (2 ${ }^{\text {a }}$ edición).

Moriyón Mojica, C. 1994. Exégesis Pragmalingüistica del Discurso Publicitario. Instituto de Ciencias de la Educación, Universidad de Valladolid: Valladolid.

Mourelle de Lema, M. 1994. El Lenguaje Publicitario. Aproximación a su Estudio. Madrid: Grujalma.

Neff Van Aertselaer, J. 1997. Language and Masculinity. Ed. S. Johnson y U. H. Meinhoff. Oxford: Blackwell.

Nixon, S. 1996. Hard Looks: Masculinities, Spectatorship and Contemporary Consumption. London: UCL.

Ortony, A. ed. 1979. Metaphor and Thought. Cambridge, Massachussets: Cambridge University Press.

Pateman, T. 1983. "How is understanding an advertisement possible?". Language, Image, Media. Eds. H. Davis y P. Walton Oxford: Blackwell: 187-204.

Pauwels, A. 1998. Women Changing Language. London and New York: Longman.

PÊCheux, M. 1982. Language, Semantics and Ideology: Stating the Obvious, traducido al inglés por H. Nagpal, Macmillan.

Peninou, G. 1976. Semiótica de la Publicidad. Barcelona: Gustavo Gili.

Pérez Chico, M. A. 2001. "Investigación para el cambio de imagen de la mujer en la publicidad". Congreso Internaciona: Mujeres, Hombres y Medios de Comunicación. Valladolid, 12- 14 noviembre.

Pingree, S., Hawkins, R. P. ; Butler; M y Paisley, W. 1976. “A scale for sexism”. Journal of Communication 26 (otoño): 193-200.

Ricoeur, P. 1978. "The metaphorical process as cognition, imagination and feeling". On Metaphor. Ed. S. E. Sacks. Chicago: IL: The University of Chicago Press: 141157.

Ross, K. 1996/1998/1999. "Against a theory of "sexist language"”. (Documento de Internet disponible en http://www.friesian.com/language.htm).

Russell, S. W. 1976 “Computer understanding of metaphorically used verbs". American Journal of Computational Intelligence. Microficha 44. 
. 1992. "Metaphoric coherence: Distinguishing verbal metaphor from "anomaly". Computational Intelligence 8, 3: 553-574.

SACKS, S. E. 1979. On Metaphor. Chicago: The University of Chicago Press.

SÁnchez Corral, L. 1991. Retórica y Sintaxis de la Publicidad (Itinerarios de la persuasión). Córdoba: Universidad de Córdoba.

. 1997. Semiótica de la Publicidad. Narración y Discurso, Madrid: Editorial Síntesis. Publicidad y Relaciones Públicas.

Schwichtenberg, C. ed. 1993. The Madonna Connection: Representational Politics, Subcultural Identities, and Cultural Theory. Boulder, Colorado: Westview Press.

Searle, J. R. 1979. "Metaphor". The Philosophy of Language. Oxford: Ed. A. P. Martinish.

Spang, K. 1979. Fundamentos de Retórica. Pamplona: Universidad de Navarra.

STEEN, G. 1994. Understanding Metaphor in Literature. London: Longman.

StRINATI, D. 1995. An Introduction to Theories of Popular Culture. London: Routledge.

STUART, S. ed. 1998. The Icon Critical Dictionary of Postmodern Thought. Cambridge: Icon.

StubBs, M. 1992. "English teaching, information technology and critical language awareness". Discourse and Social Change. Ed. N. Fairclough. London: Longman: 205-222.

1996. Text and Corpus Analysis 'Computer Assisted Studies of Language and Culture. Oxford and Massachusetts: Blackwell Publishers.

Stuteville, J. R. 1971. "Sexually polarized products and advertising strategy”. Journal of Retailing 47 (verano): 3-13.

Sweetser, E. E. 1990/1993. From Etymology to Pragmatics. Metaphorical and Cultural Aspects of Semantic Structure. Cambridge: Cambridge University Press. Cambridge Studies in Linguistics 54.

TAFLINGER, R. F. 1996. "Taking advantage”. (Documento de Internet disponible en http://www.wsu.edu.8080/ taflinger/advant.html\#in).

ТАцвот, M. 1992. "The construction of gender in a teenage magazine". Discourse and Social Change. Ed. N. Fairclough. London: Longman: 174-199.

. 1995. "A synthetic sisterhood: False friends in a teenage magazine". Eds. K. Hall y M. Bucholtz. Gender Articulated. London: Routledge. Reimpresión en D. Cameron 1998. The Feminist Critique of Language. A Reader. London and New York: Routledge: 143-165.

Press. . 1998. Language and Gender: An Introduction. Cambridge: Polity 
TANAKA, K. 1994. Advertising Language: A Pragmatic Approach to Advertisements in Britain and Japan. London: Routledge.

Thomas, L. y Wareing, S. eds. 1999. Language, Society and Power: An Introduction. London and New York: Routledge.

Turner, M. y Fauconnier, G. 1998. “Metaphor, metonymy and binding”. (Documento de Internet disponible en http://www.wam.umd.edu/ mturn/WWW/metmet.html) . 2000. "Metaphor, metonymy, and binding". Metonymy and metaphor at the crossroads. Ed. A. Barcelona. New York: Mouton de Gruyter: 133-145.

UMIKER-SEBEOK 1979/1981/1985 "Power and the construction of gendered spaces 1". International Review of Sociology/Revue Internationale de Sociologie 6 (3): 389403. (Documento de Internet disponible en http://www.slis.indiana.edu/umikerse/ papers/power.html).

Velasco SACRISTÁn, M. 1999. "Publicidad y metáfora: análisis lingüístico de las metáforas de los eslóganes de anuncios de perfumes aparecidos en las ediciones hispana y británica de Cosmopolitan en 1998”. Valladolid: Departamento de Lengua y Literatura Inglesa y Alemana. Memoria de licenciatura inédita.

. 2002 . "Publicidad y género: Propuesta, diseño y aplicación de un modelo de análisis de las metáforas de género en la publicidad impresa en lengua inglesa". Valladolid: Universidad de Valladolid. Tesis doctoral inédita.

y Fuertes Olivera. P. A. 2001. "Sexismo semiótico: Las metáforas de género en la publicidad impresa española". Congreso Internacional: Mujeres, Hombres y Medios de Comunicación. Valladolid: 12- 14 noviembre.

WeINER, J. E. 1984. “A knowledge representation approach to understanding metaphors". Computational Linguistics, 10: 1: 1-15.

Whatling, C. 1997 Screen Dreams Fantasising Lesbians in Film. Manchester: Manchester University Press.

Wilks, Y., BARNEDN. J. y WANG, J. 1991. "Your metaphor on mine: Belief ascription and metaphor interpretation". 12 ${ }^{\text {th }}$ International Joint Conference on Artificial Intelligence, ITCAI'91. San Mateo, CA: Morgan Kaufmann.

WiLson, R. D. y Moore, N. K. 1979. "The role of sexually-oriented stimuli in advertising: Theory and literature review". Advances in Consumer Research. Ed. W. WiLKIE. Ann Arbor: Association for Consumer Research: 55-61.

WinshIP, J. 1987. Inside Women's Magazines. London and New York: Pandora. 